\title{
Experimental and theoretical study of the
}

\section{chemical network of the hydrogenation of NO on interstellar dust grains}

Thanh Nguyen, ${ }^{*,+}$ Dahbia Talbi,, Emanuele Congiu, "II Saoud Baouche, ${ }^{\mathbb{I l}}$ Amir Karton, $\$$ Jean Christophe Loison," and Francois Dulieu*,II

†Present address: Institute of Low Temperature Science, Hokkaido University, Sapporo, Hokkaido 060-0819, Japan

$\ddagger L U P M$ - Laboratoire Univers et Particules de Montpellier, 34095 Montpellier Cdex 05, France IIUniversité de Cergy-Pontoise, Sorbonne Université, Observatoire de Paris, PSL Université, CNRS, LERMA, F-95000, Cergy-Pontoise, France

$\S$ School of Molecular Sciences, The University of Western Australia, Perth, Western Australia 6009, Australia

||ISM-CNRS, Universit de Bordeaux, 351 cours de la Libration, F-33405 Talence, France

E-mail: nguyenthanh@lowtem.hokudai.ac.jp; francois.dulieu@obspm.fr

\begin{abstract}
Nitrogen Monoxide (NO) is observed in the gas phase of molecular clouds. It may accrete on dust grains and there its hydrogenation should lead to hydroxylamine $\left(\mathrm{NH}_{2} \mathrm{OH}\right)$, the same way that $\mathrm{CO}$ is transformed in methanol $\left(\mathrm{CH}_{3} \mathrm{OH}\right)$ on the surface dust grains. NO hydrogenation has been said barrier-less, whereas CO hydrogenation proceed through quantum tunneling, and is thus slower. However, $\mathrm{CH}_{3} \mathrm{OH}$ is widely observed and is considered as a proxy of complex organic molecules while hydroxylamine remains undetected. We aim at studying, analyzing, and understanding the
\end{abstract}


chemical network of NO hydrogenation on cold surfaces. Experiments are carried out using a new Ultra-Hight Vacuum (UHV) set-up named VENUS. NO molecules and $\mathrm{H}$ atoms are co-deposited on a golden mirror at different temperatures. Infrared spectroscopy as well as Temperature Programmed Desorption (TPD) are used to follow the NO reactivity, with both $\mathrm{H}$ and $\mathrm{D}$, and in presence or absence of water substrate. Quantum calculations on water ice cluster models are computed separately.

During the hydrogenation of NO, 10 reactions proceed concurrently. They are identified and constrained by changing physical conditions in experiments or in calculations. Among them, we demonstrate that the $\mathrm{HNO}+\mathrm{H}$ addition reaction has a barrier which is probably crossed via quantum tunneling at $10 \mathrm{~K}$. Moreover, abstraction reactions are occurring although they are limited by $\mathrm{H}$ and $\mathrm{O}$ bonding with their environment. Chemical desorption should occur especially in absence of water which enhances the total production of hydroxylamine. The chemical network of the hydrogenation of NO has been re-investigated. Each of the 10 reactions are sorted by efficiency. We exclude the possibility of a chemical loop between $\mathrm{NO}$ and $\mathrm{HNO}$, especially in presence of water. Therefore hydroxylamine remains the main product of the hydrogenation of NO on grains and the question of its non-detection in ices or in the gas phase, specifically in shocked regions where ice mantles should be sputtered, is still open.

Keywords: Astrochemistry, molecular clouds, NO hydrogenation, dust grains, energy barriers, quantum tunneling

\section{INTRODUCTION}

With the unprecedented capability of mapping at small scale and at high sensitivity astrophysical regions, the origin and the evolution of the molecular complexity is permanently questioned. As an example Ando et al. ${ }^{1}$ has shown that chemical composition of two molecular clouds, separated by only 10 pc in the nearby galaxy NGC253, exhibit a very different chemistry. In particular, in one clump both $\mathrm{NO}$ and $\mathrm{CH}_{3} \mathrm{OH}$ are detected, 
whereas another one presents a poor chemical composition. Progressively a long and subtle inventory of possible chemical links emerges from the observations. For example we pinpoint the possible correlation of $\mathrm{HNCO}$ and $\mathrm{NH}_{2} \mathrm{CHO}^{2}$ or the possible link of O bearing compounds ${ }^{3}$. Less representative but probably equally meaningful, the non detection of $\mathrm{CH}_{2} \mathrm{OH}^{4}$ or the detection of very low concentrations of the $\mathrm{CH}_{3} \mathrm{O}$ molecule is an important but unsolved problem ${ }^{5}$. Because the chemical link in the gas phase with $\mathrm{CH}_{3} \mathrm{OH}$ is firmly established ${ }^{6}$, how to explain their non detection in shocks where $\mathrm{CH}_{3} \mathrm{OH}$ is very abundant?

The presence of methanol in the gas phase and many other hydrogenated molecules is thought to be due to the sublimation of ice mantles. The identified species of the ice such as water, carbon dioxide, formaldehyde, and methanol are formed on the cold grains, by surface reactions combining $\mathrm{H}, \mathrm{O}$ and $\mathrm{CO}, \frac{7-19}{19}$ Under dense cloud conditions, just like $\mathrm{CO}$ molecules, NO molecules can also accrete and react with many species on the surface and with $\mathrm{H}$ in particular, leading to an increase in the chemical complexity of both $\mathrm{O}$ - and $\mathrm{N}$-bearing species.

Even if the $\mathrm{NO}$ abundance is not as high as $\mathrm{CO}$, it is however relatively abundant. In circumstellar oxygen-rich envelopes NO relative abundance is as high as $10^{-6}$ (Velilla Prieto et al. ${ }^{20}$ ), whereas even in pre-stellar cores that undergo gas depletion it is still at the $1-3 \times 10^{-8}$ level. ${ }^{[21} \mathrm{NO}$ is an important gas phase molecule detected towards many dark and warm clouds with the abundance from $1 \times 10^{-8}$ to $1 \times 10^{-7}$ relative to $\mathrm{H}_{2}$ abundance ${ }^{22}$, and is at the corner-stone of the $\mathrm{N}$ and $\mathrm{O}$ chemistry. Therefore the case of the non detection of hydroxylamine $\left(\mathrm{NH}_{2} \mathrm{OH}\right)$ is an enigma, since its production by hydrogenation of NO on grains should occur without barrier ${ }^{23}$, and has other possible formation routes. ${ }^{[24}$ Taking into account the low reactivity of $\mathrm{CO}$ with $\mathrm{H}$, the absence of $\mathrm{NH}_{2} \mathrm{OH}$ in space and the omnipresence of $\mathrm{CH}_{3} \mathrm{OH}$ is questioning our understanding of their synthesis, or their destruction pathways. $\frac{1718825}{17}$

From experimental works 23126127 , a reactive network for the $\{\mathrm{NO}+\mathrm{H}\}$ reactive system 
on cold surfaces has been proposed. Five reactions were able to satisfactorily explain the measurements:

$$
\begin{gathered}
\mathrm{H}+\mathrm{H} \stackrel{\mathrm{k} 1}{\rightarrow} \mathrm{H}_{2} \\
\mathrm{NO}+\mathrm{H} \stackrel{\mathrm{k} 2}{\longrightarrow} \mathrm{HNO} \\
\mathrm{HNO}+\mathrm{H} \stackrel{\mathrm{k} 3}{\longrightarrow} \mathrm{H}_{2} \mathrm{NO} \\
\mathrm{H}_{2} \mathrm{NO}+\mathrm{H} \stackrel{\mathrm{k} 4}{\longrightarrow} \mathrm{NH}_{2} \mathrm{OH} \\
\mathrm{HNO}+\mathrm{NO} \stackrel{\mathrm{k} 5}{\longrightarrow} \mathrm{N}_{2} \mathrm{O}+\mathrm{OH}
\end{gathered}
$$

followed by

$$
\mathrm{OH}+\mathrm{H} \stackrel{\text { k6 }}{\longrightarrow} \mathrm{H}_{2} \mathrm{O}
$$

Or alternatively to $\mathrm{k} 5$ and

$$
\mathrm{HNO}+\mathrm{HNO} \stackrel{\text { k5bis }}{\longrightarrow} \mathrm{N}_{2} \mathrm{O}+\mathrm{H}_{2} \mathrm{O}
$$

However, in models is sometimes inserted the back reaction.

$$
\mathrm{HNO}+\mathrm{H} \stackrel{\mathrm{k} 2 \mathrm{~B}}{\longrightarrow} \mathrm{NO}+\mathrm{H}_{2}
$$

Reaction (8) is an abstraction reaction, well known in methylated systems ${ }^{141192829}$, or even in sulfur bearing species. ${ }^{[30}$ The $\mathrm{H}+\mathrm{HNO}$ reaction has been studied experimentally in the gas phase between 300 and $1170 \mathrm{~K}$ showing high rate constant (Glarborg et al. ${ }^{31}$ and references therein). Theoretical calculations on the same reaction (Soto and Page ${ }^{32}$ and Nguyen et al. ${ }^{33}$ ) have shown either no barrier or a small one depending on the theoretical level. A low (or no) energy barrier for this reaction may be critical as it favors looping leading to $\mathrm{H}_{2}$ formation. This kind of looping reactions $k_{2}$ and $k_{2 B}$ is a problem for astrochemical models including solid phase reactions (e.g. Vasyunin and Herbst, 34 
Ruaud et al. ${ }^{355}$ and Cuppen et al. ${ }^{36}$ ), because their inclusion in the surface reaction network dissipates a large number of $\mathrm{H}$ atoms, deviating hydrogenation processes toward simple $\mathrm{H}_{2}$ production. Therefore, the final degree of hydrogenation of the ice mantle is very sensitive to this balance of addition and abstraction mechanisms (private com. from Vasyunin et al. ${ }^{37}$ ).

Thus it is important to put into the scope of our study the possibility of abstraction reactions. We add:

$$
\mathrm{H}_{2} \mathrm{NO}+\mathrm{H} \stackrel{\mathrm{k} 3 \mathrm{~B}}{\longrightarrow} \mathrm{HNO}+\mathrm{H}_{2}
$$

and

$$
\mathrm{NH}_{2} \mathrm{OH}+\mathrm{H} \stackrel{\mathrm{k} 4 \mathrm{~B}}{\longrightarrow} \mathrm{H}_{2} \mathrm{NO}+\mathrm{H}_{2}
$$

There are 10 competing reactions on the surface, 8 actually belonging to the hydrogenation of NO. Reaction (6) is the completion of water, and reaction (1), the self-reaction of $\mathrm{H}$, is the most important from the kinetic point of view. Because it's a fast reaction only limited by H diffusion, other reactions can't compete if they are too slow, and thus the system won't evolve chemically. This paper is intended to re-investigate the chemical network of the hydrogenation of NO by examining the whole question on two fronts, from both an experimental and a theoretical approach.

The article is organized as follows: we first present methods including the experimental setup, theoretical calculations. In the next section, we show and interpret experimental results, including the study of temperature dependence, the effect of different isotopes, the role of the water substrate and the theoretical results. In the following section, we conclude results in relation to the experiments and theory. In the discussion section, we compare approaches and discuss possible astrochemical implications before summarizing in the conclusion. 


\section{METHODS}

\subsection{Experimental setup}

Experiments have been performed using the VENUS (VErs de NoUvelles Synthses) setup at the LERMA laboratory in the University of Cergy Pontoise.

The experiments were carried out under ultra-high vacuum (UHV) conditions with pressure from $1 \times 10^{-10}$ to $5 \times 10^{-10}$ mbar. Two different beams are used to deposit the reactants to the sample surface, which is constituted of a copper mirror coated with gold. The sample temperature can be controlled from $7 \mathrm{~K}$ to $350 \mathrm{~K}$ by using a regulated resistive heater. Absorption spectra of adsorbate (reactants and products) are recorded through Fourier Transform-Reflection Adsorption Infrared Spectroscopy (FT-RAIRS). Quadrupole mass spectrometer (QMS) is used 1) for probing the reactants beams before they accrete to the surface; 2) for measuring the products during the thermally programmed desorption (TPD).

VENUS has 4 different beam lines, but only two are used in this study. The top beam was used to inject the NO molecules onto the surface. The source pressure is $2.05 \times 10^{-4}$ mbar, which corresponds to a flux at the surface level of $2 \times 10^{12}$ molecules $/ \mathrm{cm}^{2} / \mathrm{s}$. The atomic hydrogen was sent to the surface through the right beam. Its flux is around $8 \times$ $10^{12}$ atoms $/ \mathrm{cm}^{2} / \mathrm{s}$. H/D atoms were generated by dissociating of $\mathrm{H}_{2} / \mathrm{D}_{2}$ molecules within a microwave discharge of $75 \mathrm{~W} / 40 \mathrm{~W}$. The dissociation efficiency of $\mathrm{H}_{2} / \mathrm{D}_{2}$ was $75 \pm 5 \%$. We use FT-RAIRS to probe the new features during the co-deposition duration. After the deposition, the products are detected with the TPD technique, which consists in measuring with the QMS the different products desorbing during the linear increase of the surface temperature $(0.2 \mathrm{~K} / \mathrm{s})$.

In order to calibrate the mono-layer of $\mathrm{NO}\left(\mathrm{ML}, 1 \mathrm{ML}=10^{15}\right.$ molecules $\left./ \mathrm{cm}^{2}\right)$, we performed series of NO TPD (like in Noble et al. ${ }^{11}$ ) with different doses deposited at $10 \mathrm{~K}$, then heated to $80 \mathrm{~K}$. Thus, we determined that $1 \mathrm{ML}$ of $\mathrm{NO}$ is obtained after 8 to 10 minutes 
of deposition. All the experiments presented here consist in co-deposition experiments, which means that $\mathrm{NO}$ and $\mathrm{H}(\mathrm{D})$ were sent simultaneously on the substrate (varied in composition, gold or water) at different temperatures, kept constant during the deposition. At the end of the co-deposition, the hydrogenation is continued for 10 minutes.

We note $\{\mathrm{NO}+\mathrm{H}\}$, the reactive system, to make the difference with the $\mathrm{NO}+\mathrm{H}(\longrightarrow$ $\mathrm{HNO}$ ) reaction. Actually as mentioned earlier the $\{\mathrm{NO}+\mathrm{H}\}$ system include at least ten reactions, and at higher temperatures, some desorption pathways can also be activated.

To understand the possible role of the substrate, we have performed similar codeposition experiments, but on a water substrate. The substrate was previously grown at a surface temperature of $10 \mathrm{~K}$ by background deposition of $5 \mathrm{ML}$ of $\mathrm{H}_{2} \mathrm{O}$. So the substrate is porous and exhibits a larger surface area due to its 3D structure, but remains almost completely accessible to deposit. $\frac{38}{38}$

\subsection{Theoretical approach}

To guide the interpretation of our experimental results, we carried out Density Functional Theory (DFT) calculations to locate the transition states on the $\mathrm{H}+\mathrm{HNO}, \mathrm{H}+\mathrm{H}_{2} \mathrm{NO}$ and $\mathrm{H}+\mathrm{H}_{2} \mathrm{NOH}$ reactions paths in the gas phase. The hybrid-meta GGA M06-2X ${ }^{39}$ functional was used for that purpose in conjunction with the aug-cc-pVTZ atomic basis set. While the M06-2X highly nonlocal functional is well suited to describe noncovalent bonds (transition states, loose complexes) it may slightly underestimate barriers. ${ }^{\sqrt[39 \mid 40]{4}}$ Therefore for the low energy transition states involved in the $\mathrm{H}+\mathrm{HNO}$ reactions (barriers below $1000 \mathrm{~K}$ ) we recalculated these barriers using the $\operatorname{CCSD}(\mathrm{T})^{41}$ method on geometries optimized at the above M06-2X level, and the explicitly correlated (F12b) version of the coupled-cluster method (CCSD(T)-F12b) ${ }^{42}$ combined to the cc-pVQZ basis set with F12 optimized (ccpVQZ-F12 $)^{43}$ and QCISD/6-311++G(d,p) geometries. Finally, because of the constant decrease of the energy barriers for the $\mathrm{H}+\mathrm{HNO}$ hydrogen abstraction reaction we used the Weizmann-4 thermochemical protocol ${ }^{\frac{4445}{145}}$ which calculates the CCSDTQ5/CBS energy 
using geometries and zero point energies optimized at the CCSD(T)/cc-pVQZ level.

To model the ice surface of the experiment we used a cluster of water molecules. To define the size of this cluster we investigated $\mathrm{HNO}-\mathrm{XH}_{2} \mathrm{O}$ complexes with $\mathrm{X}$ varying from 4 to 6 . Our full geometry optimization of these complexes demonstrated that the orientation of the HNO molecule with respect to the clusters was not affected by their size. Indeed 4 water molecules were sufficient to account for all the hydrogen bonds that bind $\mathrm{HNO}$ to the water clusters and therefore to account for the surfaces interactions between $\mathrm{HNO}$ and the water clusters. This was verified too for $\mathrm{H}_{2} \mathrm{NOH}-\mathrm{XH}_{2} \mathrm{O}$ complexes with $\mathrm{X}=4$ and 5. Limiting to 4 water molecules the size of our water cluster allowed us to study the hydrogenation of NO catalyzed by the ice at a theoretical level equivalent to the one used for the hydrogenation of $\mathrm{HNO}$ in the gaze phase, including reaction path investigations, frequency analyses and zero point energy calculations. Combining a 6-311++G(d,p) basis set to the hybrid-meta GGA M06-2X functional set we used an ultrafine integration grid for the optimization of our NO-4 $\mathrm{H}_{2} \mathrm{O}, \mathrm{HNO}-4 \mathrm{H}_{2} \mathrm{O}, \mathrm{H}_{2} \mathrm{NO}-4 \mathrm{H}_{2} \mathrm{O}$ and $\mathrm{H}_{2} \mathrm{NOH}-4 \mathrm{H}_{2} \mathrm{O}$ minima and transition state. This was required regarding the loose structure of our complexes and some of their very low frequency modes. To locate the transition state for the addition of $\mathrm{H}$ on the $\mathrm{HNO}-4 \mathrm{H}_{2} \mathrm{O}$ complex, an extensive investigation of the $\mathrm{H}-\mathrm{HNO}-4 \mathrm{H}_{2} \mathrm{O}$ hyper-surface was required. This was achieved by optimizing the $\mathrm{H}-\mathrm{HNO}-4 \mathrm{H}_{2} \mathrm{O}$ complex for each fixed distance of approach $\mathrm{H} . . . \mathrm{HNO}-4 \mathrm{H}_{2} \mathrm{O}$. The transition state was determined by locating the maximum on the calculated optimized potential energy curve.

Finally, we determined the binding energies to the 4 water cluster, of the NO, $\mathrm{HNO}$, $\mathrm{H}_{2} \mathrm{NO}$ and $\mathrm{NH}_{2} \mathrm{OH}$ molecules as the difference between the energy of the molecules bond to the water cluster and the sum of the energies of the water cluster and of the molecules. We also calculate the binding energy using our model developed in Wakelam et al. ${ }^{46}$ All calculations have been done using either Gaussian 09 ${ }^{47}$ or MOLPRO ${ }^{48}$ quantum chemistry codes. 


\section{RESULTS AND DISCUSSION}

\subsection{Theoretical results}

\subsubsection{The $\mathrm{H}+\mathrm{HNO}$ abstraction reaction}

Experimental results on the $\mathrm{H}+\mathrm{HNO}$ reaction in the gas phase have pointed out for a high rate constant with a low barrier in the entrance valley. ${ }^{3149}$ Previous MP2 and QCISD theoretical calculations on the abstraction pathway have led to a small barrier of $2 \mathrm{~kJ} / \mathrm{mol}, \frac{33}{3}$ shown to vanish at the MRCI level. ${ }^{32}$ Our present theoretical investigations using the Weizmann-4 thermochemical protocol see Table 2 in the Supporting information confirm that there is no barrier for this abstraction reaction. Since this approach has been found to give thermochemical properties (such as atomization energies) with sub-kJ/mol $95 \%$ confidence intervals from highly accurate experimental determinations, $\frac{50}{6}$ we can confidently confirm that this reaction is barrier-less in the gas phase a statement that cannot be generalized to the same reaction on the ice. Indeed our theoretical investigations show that $\mathrm{HNO}$ is bound to the 4 water cluster through two hydrogen bonds (Table 4 in the supporting information) involving respectively the oxygen and hydrogen atoms of HNO. Such a position with respect to the cluster prevents the hydrogen abstraction reaction $\mathrm{H}$ $+\mathrm{HNO}-4 \mathrm{H}_{2} \mathrm{O}$ to occur. Indeed, in the gas phase (Table 2 in the Supporting information) the abstraction pathway requires a quasi-linear H...HNO approach (with an HHN angle close to $180^{\circ}$ ). Such an approach, as confirmed by our attempt to constrain the abstraction reaction on $\mathrm{HNO}$ adsorbed on the water cluster is very repulsive, forcing the $\mathrm{H}$ atom to follow the valley corresponding the addition reaction path.

\subsubsection{The $\mathrm{H}+\mathrm{HNO}$ addition reaction}

For the addition of $\mathrm{H}$ on the nitrogen atom our results from Table 2 in the Supporting information show that this reaction presents a barrier of $6.6 \mathrm{~kJ} / \mathrm{mol}$ at the DFT level $(12.8 \mathrm{~kJ} / \mathrm{mol}$ at the CCSDTQ5/CBS level). At the same DFT level, this barrier is almost 
unchanged when $\mathrm{HNO}$ is on the 4 water cluster i.e. $(6.1 \mathrm{~kJ} / \mathrm{mol}$-Table 5 in the Supporting information); the difference is less than $10 \%$. The 4 water cluster has almost no catalytical effect on the reactivity of $\mathrm{H}$ with $\mathrm{HNO}$ bound to the water cluster. The addition of $\mathrm{H}$ on the oxygen atom of HNO presents a very high energy barrier in the gas phase (Table 2 in the Supporting information). We did not investigate this reaction with HNO on the 4 water cluster because of this high barrier, which we do not expect to be reduced to the level that this reaction could become efficient on the ice.

\subsubsection{The $\mathrm{H}+\mathrm{H}_{2} \mathrm{NO}$ reaction}

Even though we expected the addition of $\mathrm{H}$ on $\mathrm{H}_{2} \mathrm{NO}$ to form $\mathrm{H}_{2} \mathrm{NOH}$ to be barrier-less in the gas phase we checked this point by investigation this reaction path at the both M062X/aug-cc-pVTZ and QCISD/6-311++G(d,p) levels . We also investigated the addition of $\mathrm{H}$ on $\mathrm{H}_{2} \mathrm{NO}$ bound to the 4 water cluster and similarly we saw no evidence for the existence of a transition state for the formation of the $\mathrm{H}_{2} \mathrm{NOH}-4 \mathrm{H}_{2} \mathrm{O}$ complex. It is interesting to notice here that the $\mathrm{OH}$ bond of $\mathrm{H}_{2} \mathrm{NOH}$ is involved in a hydrogen bond with one of the oxygen of the water cluster (Table 4 in the Supporting information) with a consequence on its reactivity that will be discussed latter.

\subsubsection{The $\mathrm{H}+\mathrm{H}_{2} \mathrm{NOH}$ reaction}

For this reaction, only the gas-phase mechanism have been considered. Our DFT calculations (Table 3 in the Supporting information) show that the two possible abstraction reactions for the formation of $\mathrm{H}_{2} \mathrm{NO}$ and $\mathrm{NHOH}$ can compete, having similar energy barriers. On the ice one would expect the formation of $\mathrm{NHOH}$ to be favored because of the orientation of $\mathrm{H}_{2} \mathrm{NOH}$ with respect to the surface of the ice. 


\subsection{Experimental results}

\subsubsection{Completeness of the reactions of the $\{\mathrm{NO}+\mathrm{H}\}$ system before the TPD}

Because the TPD diagnostic requires the heating of the sample, it is important to know if all the initial reactants are consumed during the co-deposition phase. The use of the infrared spectroscopy gives precious indications because it can be performed during the reacting phase so before any thermal transformation of the sample. It is sometimes called in situ measurements. Figure 1 shows in red the IR spectrum recorded after NO deposition (without co-deposition of $\mathrm{H}$ ). We can see the characteristic, $\mathrm{N}=\mathrm{O}$ asymmetric stretch $v_{5}$ and the $\mathrm{N}=\mathrm{O}$ symmetric stretch $v_{1}$, observed at 1770 and $1860 \mathrm{~cm}^{-1}$, respectively, of NO dimer. ${ }^{2351}$ In blue is displayed the IR spectrum obtained after the co-deposition of $\mathrm{NO}$ and $\mathrm{H}$ on the gold surface held at $10 \mathrm{~K}$. NO dimer (or monomer) features are no longer detectable, what we observe is a peak at $2233 \mathrm{~cm}^{-1}$ which is attributed to $\mathrm{N}_{2} \mathrm{O}$. We note here that the IR features of $\mathrm{NH}_{2} \mathrm{OH}$ is composed of broad bands from (900 $1800) \mathrm{cm}^{-1}$ and $(2700-3500) \mathrm{cm}^{-1}$, that are hardly detectable and furthermore unusable for quantitative analysis under our experimental conditions, because of their relative low contrasts compared to narrower peaks such as those of $\mathrm{NO}$ or $\mathrm{N}_{2} \mathrm{O}$. No evolution of the IR signal is observable during the heating phase of the TPD, except of course the disappearance of the $\mathrm{N}_{2} \mathrm{O}$ peak due to its desorption of $\mathrm{N}_{2} \mathrm{O}$.

These results are similar to those previously published ${ }^{2327}$. Taking into account the sensitivity of the method, we note that more than $90 \%$ of the NO should have reacted during the co-deposition phase so at low temperatures.

We show the TPD curves in figure 2. For pure $\{\mathrm{NO}\}$ experiments (in red) we observe a desorption peak at around $50 \mathrm{~K}$. In blue is displayed the desorption after the $\{\mathrm{NO}+\mathrm{H}\}$ reactive system completion. We can clearly see both $\mathrm{N}_{2} \mathrm{O}$ desorption (140-160 K) and $\mathrm{NH}_{2} \mathrm{OH}$ desorption $(160-200 \mathrm{~K})$. Their ratios are clearly indicating that $\mathrm{NH}_{2} \mathrm{OH}$ is the major product, whereas $\mathrm{N}_{2} \mathrm{O}$ is the minor product. 


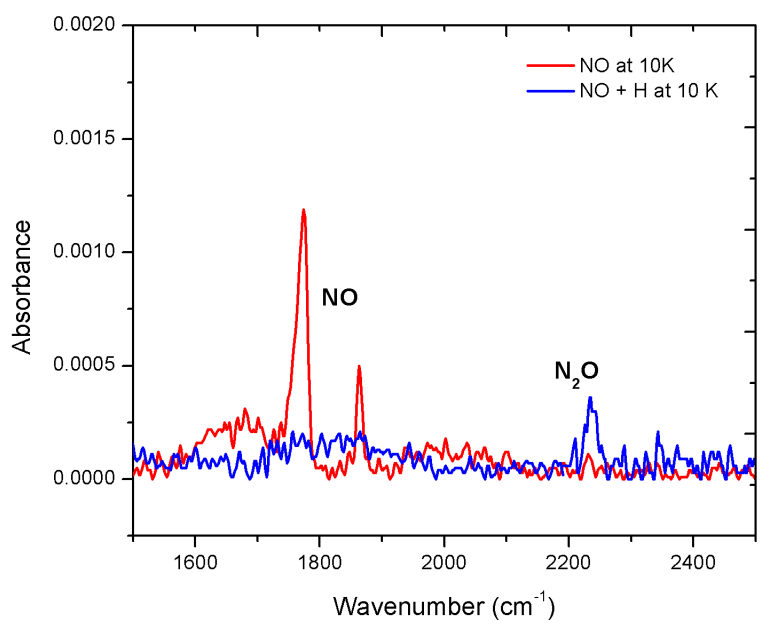

Figure 1: IR spectra obtained after the deposition of $4 \mathrm{ML}$ of $\mathrm{NO}$ at $10 \mathrm{~K}$ on gold (red line), and after NO (4ML) and H (16 ML) co-deposition (blue line).

Around $50 \mathrm{~K}$, there is still a weak desorption of $\mathrm{NO}$, slightly shifted and broadened compared with the case of pure $\{\mathrm{NO}\}$ experiments, indicating some remaining $\mathrm{NO}$. However, the NO consumption is $\sim 90 \%$, in agreement with IR spectra. The shift and broadening of the peak is due to the change of the molecular surrounding of the desorbing NO. Actually, in case of $\{\mathrm{NO}+\mathrm{H}\}$ experiments the $\mathrm{NO}$ molecules have to escape from an ice film now composed in majority of $\mathrm{NH}_{2} \mathrm{OH}$ and $\mathrm{N}_{2} \mathrm{O}$. These two compounds are desorbing at higher temperatures ( $\sim 180 \mathrm{~K}$ and $\sim 150 \mathrm{~K}$, respectively) and therefore are slightly delaying the NO desorption.

The remaining $\mathrm{NO}$ could originate from incomplete $\mathrm{NO}$ consumption, although we cannot exclude some default in our physical beams overlap on the sample, making a geometrical zone of $\mathrm{NO}$ less exposed to $\mathrm{H}$ atoms. Longer $\mathrm{H}$ expositions time on thinner NO films, however, rule out this possibility. Under these conditions we can achieve a full NO disappearance. More reasonably, we can suppose that the remaining part of NO is due to an insufficient total number of $\mathrm{H}$ atoms compared to $\mathrm{NO}$ molecules, but it is also possible that a back reaction $\mathrm{HNO}+\mathrm{H} \longrightarrow \mathrm{NO}+\mathrm{H}_{2}$ (reaction 8) impedes a complete consumption of $\mathrm{NO}$ by repopulating NO from is product $\mathrm{HNO}$. This possibility will be 
discussed later.

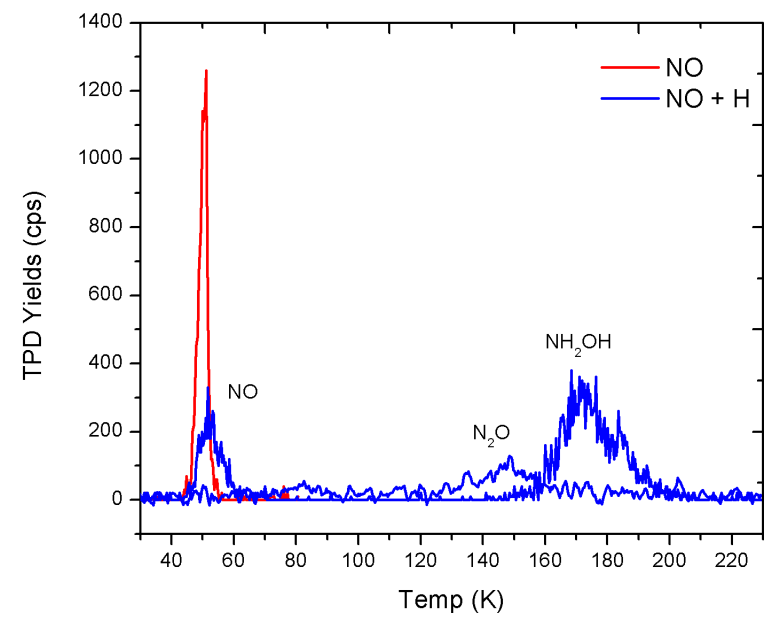

Figure 2: TPD profiles of pure $\{\mathrm{NO}\}$ (red curve) and $\{\mathrm{NO}+\mathrm{H}\}$ (blue curves). $m / z 30,33$ and 44 are displayed corresponding respectively to $\mathrm{NO}, \mathrm{N}_{2} \mathrm{O}$ and $\mathrm{NH}_{2} \mathrm{OH}$

\subsubsection{Temperature dependency}

In previous experiments, reactivity of $\mathrm{NO}$ with $\mathrm{H}$ has been tested at different temperatures $^{23}$, up to $42 \mathrm{~K}$ using porous amorphous ice as a substrate. The aim was to establish that the $\mathrm{H}+\mathrm{NO}$ reaction is barrier-less. However, only $\mathrm{NO}$ consumption was tested, and no products were analyzed. Such product analysis was conducted only for experiments performed on surfaces held at $10 \mathrm{~K}$.

Here we present new results that show the main products of NO hydrogenation, namely hydroxylamine $\left(\mathrm{NH}_{2} \mathrm{OH} m / z=33\right)$ and nitrous oxide $\left(\mathrm{N}_{2} \mathrm{O} m / z=44\right)$ for two surface temperatures of $8 \mathrm{~K}$ and $40 \mathrm{~K}$, respectively (Figure 3 ). For both experiments, there is a remaining part of NO. It corresponds to the desorption peak at around $50 \mathrm{~K}$ (green curve). The other features of $m / z=30$ at higher temperature are due to the cracking patterns of both $\mathrm{NH}_{2} \mathrm{OH}$ (peak at 160-200 K) and $\mathrm{N}_{2} \mathrm{O}$ (around 140-170 K). More important is the extreme difference in intensity of the $\mathrm{NH}_{2} \mathrm{OH}$ and $\mathrm{N}_{2} \mathrm{O}$ TPD peaks. At $8 \mathrm{~K}, \mathrm{NH}_{2} \mathrm{OH}$ is the major product whereas at $40 \mathrm{~K} \mathrm{~N}_{2} \mathrm{O}$ becomes the major product and $\mathrm{NH}_{2} \mathrm{OH}$ is almost 

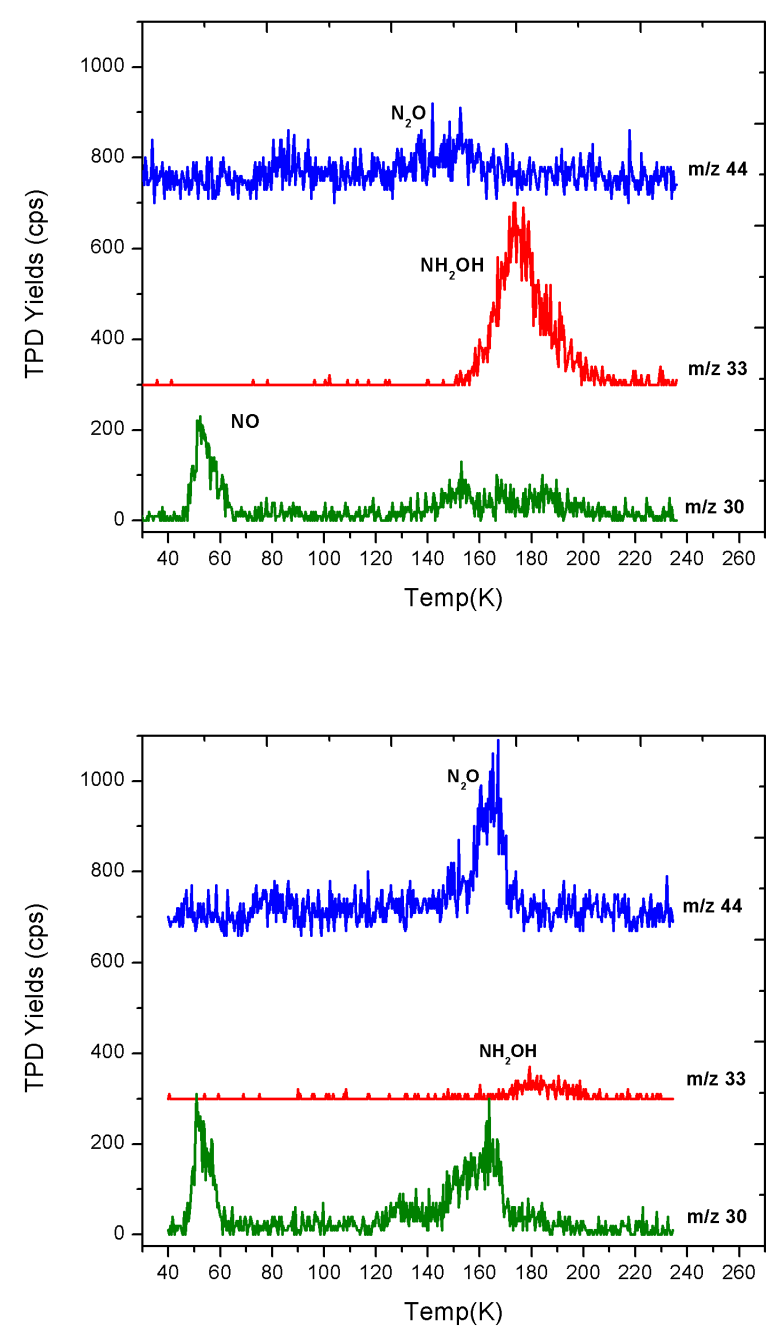

Figure 3: Influence of the surface temperature: TPD traces of $m / z=30$ (NO, green lines), $m / z=33\left(\mathrm{NH}_{2} \mathrm{OH}\right.$, red lines) and $m / z=44\left(\mathrm{~N}_{2} \mathrm{O}\right.$, blue lines) for co-deposition experiments of $\{\mathrm{NO}+\mathrm{H}\}$ on gold substrate held at $8 \mathrm{~K}$ (upper panel), and $40 \mathrm{~K}$ (lower panel). Curves are offset for clarity purpose. 
present in trace amounts. We calculated the ratio of the integrated TPD areas between $\mathrm{NH}_{2} \mathrm{OH}$ and $\mathrm{N}_{2} \mathrm{O}$, it is 6.7 at $8 \mathrm{~K}$, and 0.01 at $40 \mathrm{~K}$.
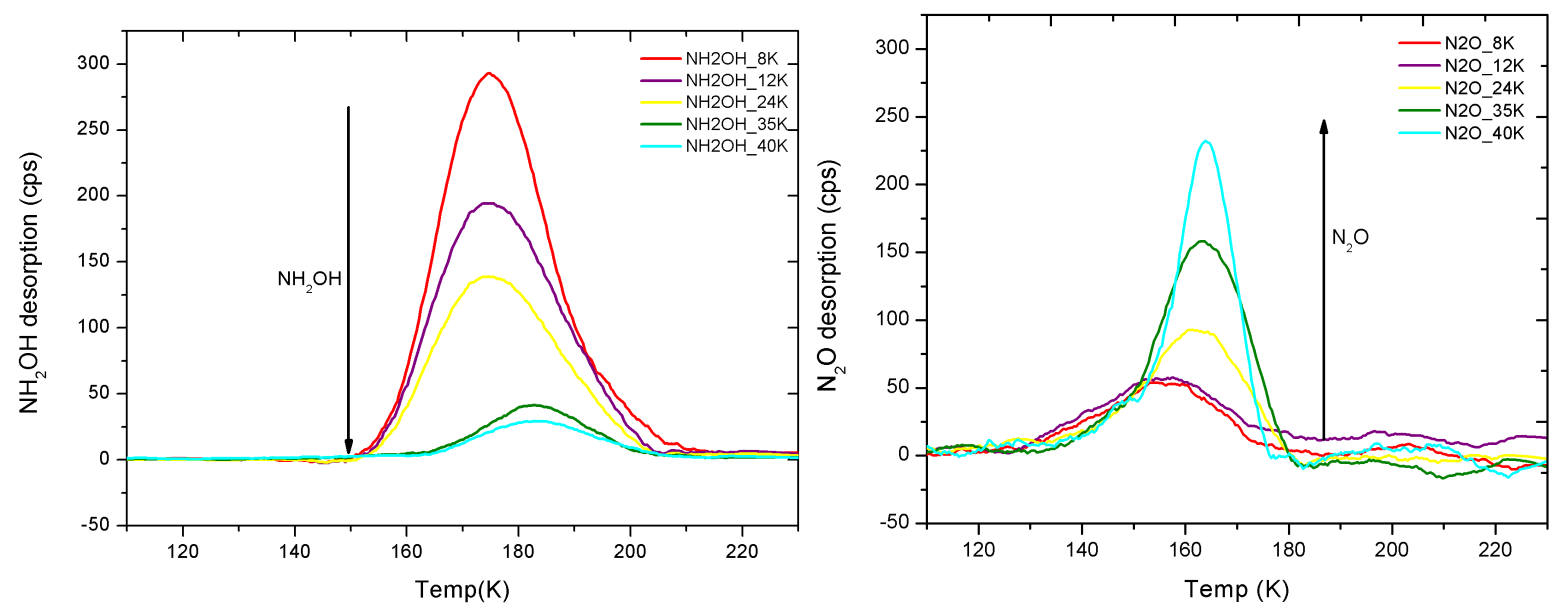

Figure 4: TPD traces of $\mathrm{NH}_{2} \mathrm{OH}$ (left panel) and $\mathrm{N}_{2} \mathrm{O}$ (right panel) at different surface temperatures. Each temperature $(8,12,24,35,40 \mathrm{~K})$ corresponds to one specific codeposition experiment $\{\mathrm{NO}+\mathrm{H}\}$. Curves are smoothed by adjacent averaging for a better visibility. $\mathrm{NH}_{2} \mathrm{OH}$ amount decreases with $\mathrm{T}_{s}$ whereas $\mathrm{N}_{2} \mathrm{O}$ increases. The vertical black arrows represent the evolution of the peak with the temperature of the substrate.

Figure 4 shows the TPD series of $\mathrm{NH}_{2} \mathrm{OH}$ (left panel) and $\mathrm{N}_{2} \mathrm{O}$ (right panel) at different surface temperatures. By looking at $\mathrm{NH}_{2} \mathrm{OH}$ and $\mathrm{N}_{2} \mathrm{O}$ peaks, we see a clear decrease in $\mathrm{NH}_{2} \mathrm{OH}$, whereas $\mathrm{N}_{2} \mathrm{O}$ yield is increasing with the surface temperature. We have calculated the integrated area of $\mathrm{NH}_{2} \mathrm{OH}$ and $\mathrm{N}_{2} \mathrm{O}$ desorption peak for each temperature, and plotted the result in Figure 5. We can see an exchange of the chemical output of the $\{\mathrm{NO}+\mathrm{H}\}$ reactive system. There is a decrease in $\mathrm{NH}_{2} \mathrm{OH}$, which can be fitted by an exponential decay, while the $\mathrm{N}_{2} \mathrm{O}$ yield may exhibit a double increment, one at the lowest temperature and the other one at around $30 \mathrm{~K}$.

The main learning that comes from this new set of experiment is that the ratio between the different reactions vary with surface temperature. The yields of all kinetic experiments, as those presented here, are always the result of a competition between the different reactions. Every single reaction rate evolves differently with temperature. In the given set of equations we can distinguish and classify some of them. Reaction $1\left(\mathrm{H}+\mathrm{H} \longrightarrow \mathrm{H}_{2}\right)$, is central to this reactive system, since it regulates the $\mathrm{H}$ surface density, so the efficiency 


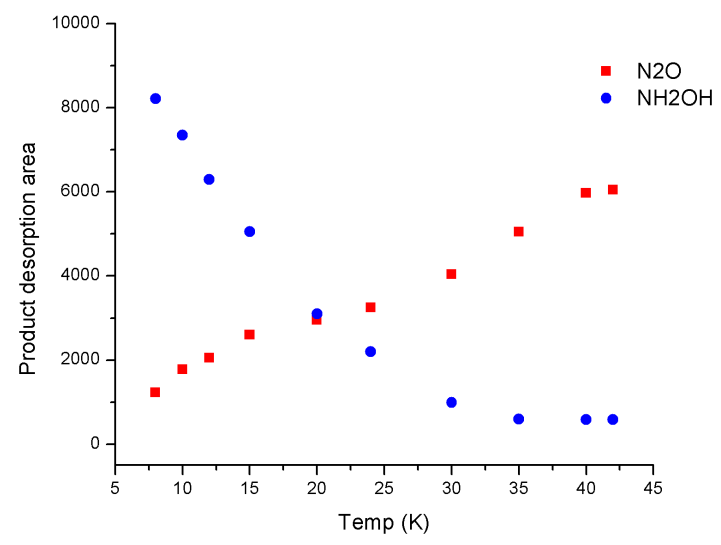

Figure 5: Integrated areas of $\mathrm{NH}_{2} \mathrm{OH}$ (blue circles) and $\mathrm{N}_{2} \mathrm{O}$ (red squares) desorptions as a function of the surface temperature, obtained after the same co-deposition of $\mathrm{NO}$ and $\mathrm{H}$.

of the hydrogenation. In absence of any other reactants, the $\mathrm{H}$ surface density reduces with surface temperature. Between 8 and $14 \mathrm{~K}$ it is due to the increase in the $\mathrm{H}$ mobility that limits the reaction. At higher temperature, desorption of $\mathrm{H}$ start to be significant and opens a new competitive exit channel. However, even if the residence time of $\mathrm{H}$ is very short, reaction $2(\mathrm{NO}+\mathrm{H} \longrightarrow \mathrm{HNO})$ turns out to be faster since the chemical network is fed by this reaction and also $\mathrm{NO}$ is still highly consumed at $42 \mathrm{~K}$.

To calculate a rate such as $k_{1}$ or $k_{2}$, it is usually assumed that it can be decomposed in different parts, one which is intrinsic to the reaction, and corresponds to the probability per attempt to cross the barrier, and one which depends on the conditions which are determining the number of attempts per second, so the diffusion and the surface density (or concentration). As an example we write $\mathrm{k}_{1}$ and $\mathrm{k}_{2}$.

$$
\begin{gathered}
k_{1}=k_{\operatorname{diff}(H)} p_{R 1}[H][H] \\
k_{2}=k_{\operatorname{diff}(\mathrm{NO}, H)} p_{R 2}[N O][H]
\end{gathered}
$$

where $[\mathrm{H}]$ is the surface density of $\mathrm{H}$.

In first approximation we can consider that the diffusion is dominated by $\mathrm{H}$ diffusion 
so the diffusive terms $k_{\operatorname{diff}(N O, H)} k_{\operatorname{diff}(H)}$ are equal. Moreover, the probability to overcome the barrier of reaction $p_{R 1}$ and $p_{R 2}$ are equal and close to unity because the two reactions are associating two radicals. Therefore, we can see that once the $[\mathrm{NO}]$ surface concentration is larger than the $[\mathrm{H}]$ surface concentration, the rate $k_{2}$ will dominate over $k_{1}$.

Therefore a decrease of $[\mathrm{H}]$ does not necessarily reduce the efficiency of reaction 2 . because it affects firstly reaction 1 due to the square function of $[\mathrm{H}]$. Having verified that reaction $4\left(\mathrm{H}_{2} \mathrm{NO}+\mathrm{H} \longrightarrow \mathrm{NH}_{2} \mathrm{OH}\right)$ on the 4 water cluster is also barrier-less, it should proceed promptly as soon as some $\mathrm{H}_{2} \mathrm{NO}$ is appearing on the surface, and should be kinetically behaving like reaction 2 . Reactions 5 and 7 , which lead to $\mathrm{N}_{2} \mathrm{O}$ and $\mathrm{H}_{2} \mathrm{O}$, are not hydrogenation reactions. Therefore, the limiting factor compared to hydrogenation reactions for these reactions is certainly the diffusive part of the reaction because the diffusion of $\mathrm{H}$ is believed to dominate over all other species diffusion. At low temperatures, only the increase of the surface density of $\mathrm{HNO}$, so the relative inefficiency of its destruction, is able to explain why at $10 \mathrm{~K}$ we can observe the formation of $\mathrm{N}_{2} \mathrm{O}$.

Now we have to consider other reactions, especially reaction $3\left(\mathrm{HNO}+\mathrm{H} \longrightarrow \mathrm{H}_{2} \mathrm{NO}\right.$ ), which enables the formation of hydroxylamine. We have seen before that the environmental part (diffusion and surface concentration) of the rate $k_{3}$ is very favourable. It is hydrogen addition so the diffusion is about the same level as other hydrogenation, and follow the same temperature trend, and the surface concentration of HNO is likely to be high enough to accelerate reaction 5 . Therefore, the limiting factor should be the probability $p_{R 3}$ which is lower than other hydrogenation reactions, implying a barrier to the reaction. From our theoretical investigations we have located a barrier of $734 \mathrm{~K}$ for the addition of a $\mathrm{H}$ atom on the nitrogen of $\mathrm{HNO}$ adsorbed on the water cluster. We have also calculated for the $\mathrm{HNO}+\mathrm{H} \longrightarrow \mathrm{NHOH}$ reaction a barrier above $10000 \mathrm{~K}$ (Table 3 in the supporting information). Since the ice surface is not expected to lower such a high barrier at a level where tunneling could become efficient, this reaction should be a minor one on the ice. Therefore, as we observe a relative decrease in hydroxylamine with temperature, 
likely due to reaction 3 , and since we have located a low energy barrier for $\mathrm{H}+\mathrm{HNO}-4 \mathrm{H}_{2} \mathrm{O}$ reaction, it is fair to suppose that this addition proceed via tunneling.

Figure 6 shows a sketch of the $\{\mathrm{NO}+\mathrm{H}\}$ reactive system, including the main change with temperature of the chemical pathways, which is probably induced by the different dependency on the temperature of reaction 3 if compared to other hydrogenation reactions.

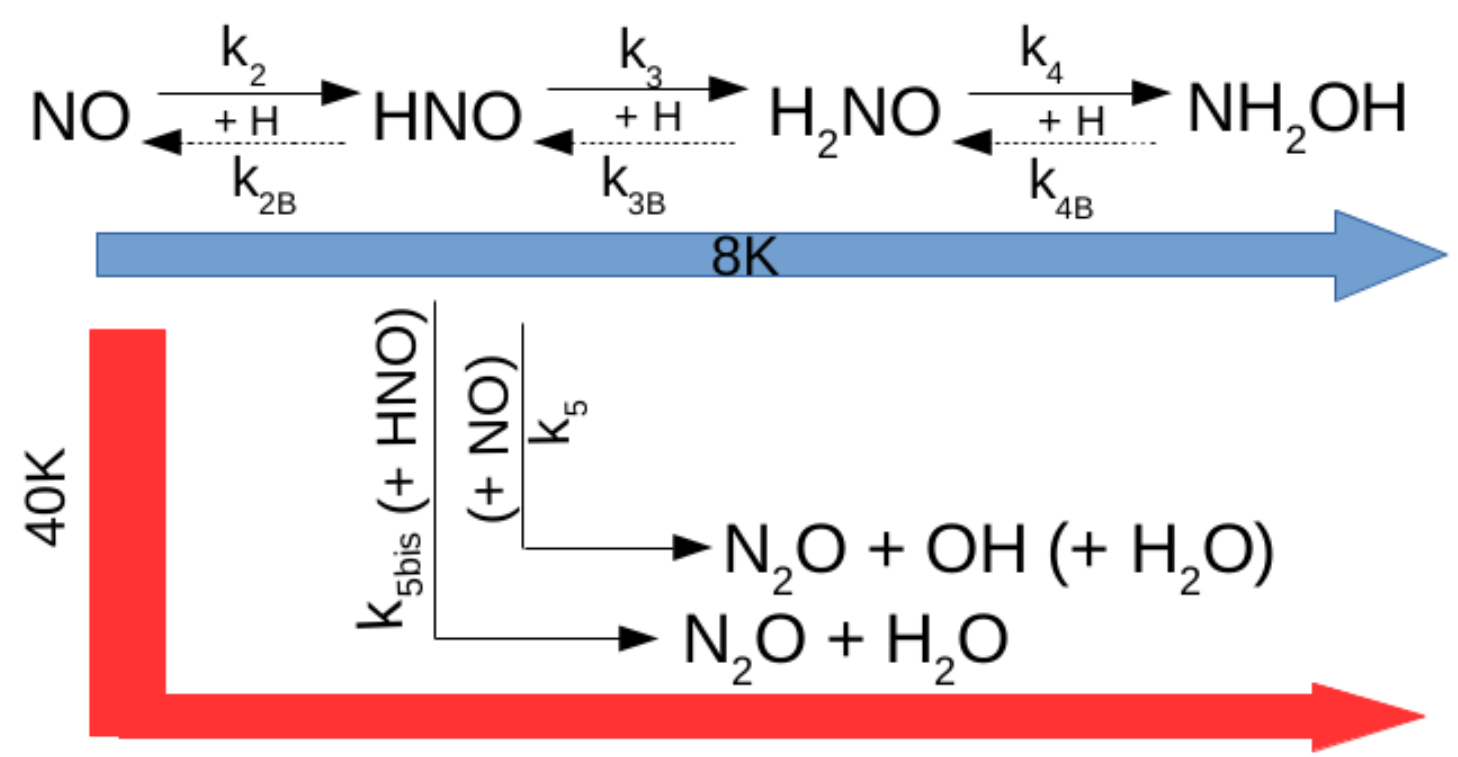

Figure 6: Sketch of the $\{\mathrm{NO}+\mathrm{H}\}$ reactive system as it proceeds at $8 \mathrm{~K}$ (blue arrow, and and $40 \mathrm{~K}$ (red arrow).

\subsubsection{The $\{\mathrm{NO}+\mathrm{D}\}$ reactive system at various temperatures}

It is possible to test the hypothesis of the reaction proceeding through quantum tunneling by substituting $\mathrm{H}$ atoms by $\mathrm{D}$ atoms. Indeed, the mass variation is supposed to lower considerably the reaction rate in case of quantum tunneling.

Figure 7 shows the TPD profiles of the $\{\mathrm{NO}+\mathrm{D}\}$ co-deposition experiment for a surface held at $10 \mathrm{~K}$. ND $\mathrm{ND}_{2} \mathrm{OD}$ desorbs between $170 \mathrm{~K}$ and $190 \mathrm{~K}$ a,nd $\mathrm{N}_{2} \mathrm{O}$ between $140 \mathrm{~K}$ and $180 \mathrm{~K}$. The presence of the two main products indicates that the reactive network is similar but if we consider the height of the peak of hydroxylamine, we can see by comparison 


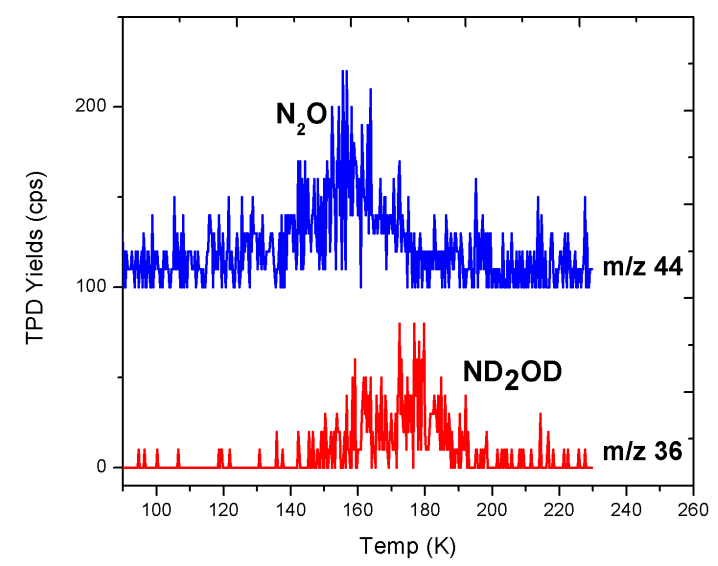

Figure 7: TPD profiles of masses $m / z=36$ a.m.u. (in red) and $m / z=44$ (in blue) corresponding to $\mathrm{ND}_{2} \mathrm{OD}$ and $\mathrm{N}_{2} \mathrm{O}$, respectively, recorded after a co-deposition experiment of $\{\mathrm{NO}+\mathrm{D}\}$ at $10 \mathrm{~K}$.

with Figure 3 that it is relatively smaller, whereas $\mathrm{N}_{2} \mathrm{O}$ is about the same size.

Table 1: Ratios of the TPD areas of $\mathrm{N}_{2} \mathrm{O}, \mathrm{NH}_{2} \mathrm{OH}$ (or $\mathrm{ND}_{2} \mathrm{OD}$ ) obtained after co-deposition experiments and the TPD area of $\mathrm{NO}$ in the pure $\mathrm{NO}$ experiment (indicated by $\left.\mathrm{NO}^{*}\right)$. $\{\mathrm{NO}$ $+\mathrm{D}\}$ and $\{\mathrm{NO}+\mathrm{H}\}$ are performed on a gold substrate hold at $10 \mathrm{~K}$ whereas $\{\mathrm{NO}+\mathrm{H}+$ $\left.\mathrm{H}_{2} \mathrm{O}\right\}$ is made on $\mathrm{H}_{2} \mathrm{O}$ substrate.

\begin{tabular}{|c|c|c|c|}
\hline Experiment & $\mathrm{N}_{2} \mathrm{O} / \mathrm{NO}^{*}$ & $\mathrm{NX}_{2} \mathrm{O} / \mathrm{NO}^{*}$ & $\mathrm{NO} / \mathrm{NO}^{*}$ \\
\hline$\left\{\mathrm{NO}^{*}\right\}$ & $<2 \%$ & $<1 \%$ & $100 \%$ \\
$\{\mathrm{NO}+\mathrm{D}\}$ & $16 \%$ & $8 \%$ & $25 \%$ \\
$\{\mathrm{NO}+\mathrm{H}\}$ & $14 \%$ & $53 \%$ & $13 \%$ \\
$\left\{\mathrm{NO}+\mathrm{H}+\mathrm{H}_{2} \mathrm{O}\right\}$ & $12 \%$ & $82 \%$ & $2 \%$ \\
\hline
\end{tabular}

Table 1 presents the relative production of $\mathrm{N}_{2} \mathrm{O}$ and $\mathrm{NH}_{2} \mathrm{OH}$ (or $\mathrm{ND}_{2} \mathrm{OD}$ ), at the end of co-deposition experiments performed at $10 \mathrm{~K}$. We divide the TPD areas of the products by the TPD area of NO molecules obtained during the $\{\mathrm{NO}\}$ experiment. We have added a star in the $\mathrm{NO}^{*}$ case to emphasize that the normalization is not done with respect to the remaining $\mathrm{NO}$ in each experiments, but according to the amount of $\mathrm{NO}$ obtained in the pure $\mathrm{NO}$ experiment. Therefore, the ratio $\mathrm{NO} / \mathrm{NO}^{*}$ is $100 \%$ for the first experiment. We first point out that the efficiency of detection of the QMS is not exactly equal from one molecule to the other. It can vary within a few tens of $\%$ for these molecules. It is due to 
the different ionization cross sections (which could be calculated), but also to the different spatial and kinetic distributions of the different desorbing species (which is unknown). We added TPD areas of all the cracking patterns of a given molecule. This can be done even for masses showing several peaks such as mass 30 , which is attributed to 3 parent molecules $\left(\mathrm{NO}, \mathrm{N}_{2} \mathrm{O}, \mathrm{NH}_{2} \mathrm{OH}\right)$, because they these species not desorb in the same window of temperature. As a conclusion, the ratios presented in the table do not exactly represent the ratios of the species, but they give a good indication. In the same column, the relative error is similar, so if we underestimate or overestimate a species, we do the same for all the experiments. Therefore, if the absolute values can be debated, the relative values are reliable.

In Table 1 we first notice that the total yield for the $\{\mathrm{NO}+\mathrm{H}\}$ experiment is $80 \%$ of the deposited dose. It is less than 100\% which could be due to the inaccuracy of the method. But this is certainly not an explanation for the $\{\mathrm{NO}+\mathrm{D}\}$ experiment whose total yield is $49 \%$. So there are missing products in the deuterium experiment.

Our hypothesis is that some of the products are lost because of the chemical desorption (or reactive desorption). The chemical desorption is the direct return to the gas phase of a newly formed molecule on a surface due to the excess energy released in case of an exothermic reaction. ${ }^{[52}$ Following our previous findings, $\stackrel{5354}{5}$ this is very likely to occur when the excess of chemical energy is large and when the products have a small number of atoms, such as in the following reactions for example:

$$
\begin{gathered}
\mathrm{NO}+\mathrm{H} \longrightarrow \mathrm{HNO}_{\text {gas }} \\
\mathrm{HNO}+\mathrm{H} \longrightarrow \mathrm{NO}_{\text {gas }}+\mathrm{H}_{2} \\
\mathrm{HNO}+\mathrm{H} \longrightarrow \mathrm{NO}+\mathrm{H}_{2 \text { gas }}
\end{gathered}
$$

However, the chemical desorption efficiency is not believed to change dramatically by substitution of isotope, and remains a relatively low probability effect $(<10-20 \%$ per 
reaction) most of the time. So we conclude that to increase the loss of products (i.e., species that go to the gas phase), the efficiency of some reactions should increase, and that probably reactions 8 and 12 , which are abstraction reactions, are enhanced in the case of the $\{\mathrm{NO}+\mathrm{D}\}$ experiment.

Indeed, as the abstraction reaction 8 and 12 have much smaller barriers than addition reactions, they are enhanced for $\mathrm{D}$ atoms as tunneling is less efficient for $\mathrm{D}$ than it is for $\mathrm{H}$. Thus the reaction

$$
\mathrm{DNO}+\mathrm{D} \longrightarrow \mathrm{D}_{2} \mathrm{NO}
$$

is unfavored with respect to

$$
\mathrm{DNO}+\mathrm{D} \longrightarrow \mathrm{NO}+\mathrm{D}_{2}
$$

From Table 1 we can see that the production of $\mathrm{N}_{2} \mathrm{O}$ may be higher, but it is at the limit of our experimental uncertainties. The increase of DNO on the surface, that is induced by the reduction of the second step of deuteration favors the $\mathrm{N}_{2} \mathrm{O}$ production. However the absence of mobility of the reactants at low temperature, keep the yield relatively low, because $\mathrm{N}_{2} \mathrm{O}$ does not come directly from an hydrogenation reaction. So, the only remaining possibility for $\mathrm{DNO}$ is to react via the back reaction 8 , which favors the chemical desorption, hence the prompt release of molecules into the gas phase.

Figure 8 compares the yields of $\mathrm{NH}_{2} \mathrm{OH}$ and $\mathrm{ND}_{2} \mathrm{OD}$ after $\{\mathrm{NO}+\mathrm{H}\}$ and $\{\mathrm{NO}+\mathrm{D}\}$ experiments carried out at different surface temperatures. We can see that the trend is similar. Hydroxylamine is less efficiently produced when the temperature is increased. But the hydrogenation is always more efficient than the deuteration, especially at low temperatures. On the other hand, the formation yield of $\mathrm{N}_{2} \mathrm{O}$ is slightly favored in the deuteration experiments, but the most striking point is the lost of a large fraction of the initial reactants, probably expelled from the surface due to the chemical desorption. This 
non-thermal desorption efficiency is enhanced in the case of reactions that proceed in both directions. We can conclude that $\mathrm{DNO}+\mathrm{D} \longrightarrow \mathrm{D}_{2} \mathrm{NO}$ is much slower than $\mathrm{HNO}+\mathrm{H} \longrightarrow$ $\mathrm{H}_{2} \mathrm{NO}$. This is an indication that quantum tunneling should be at play for this specific reaction. This is consistent with our calculated low energy barrier for this reaction. Of course, it could also be an effect of zero-point energy shift, D atoms lying usually deeper in adsorption wells, and therefore may have a higher barrier to cross. However, in this peculiar case one has to explain why the abstraction reaction $\mathrm{DNO}+\mathrm{D} \longrightarrow \mathrm{NO}+\mathrm{D}_{2}$ is relatively more efficient than the reaction $\mathrm{HNO}+\mathrm{H} \longrightarrow \mathrm{NO}+\mathrm{H}_{2}$. Our best explanation remains that reaction 3 has a higher barrier than reaction 8 , and that reaction 3 should be overcome via quantum tunneling.

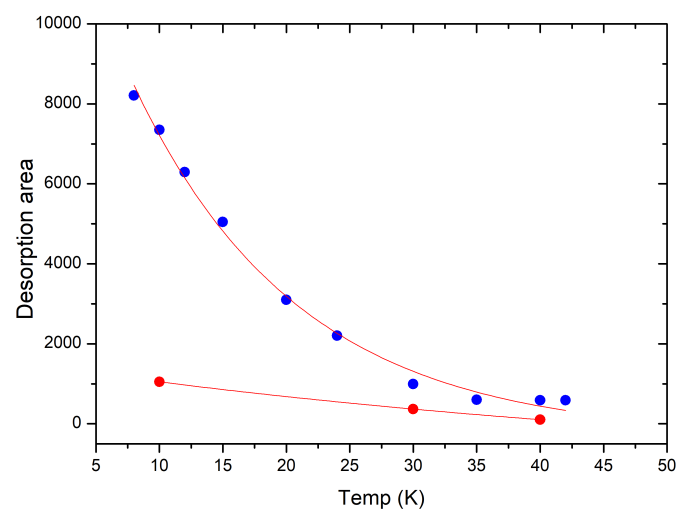

Figure 8: Blue circles: $\mathrm{NH}_{2} \mathrm{OH}$ integrated areas after the co-deposition of $\mathrm{NO}$ molecules and $\mathrm{H}$ atoms. Red circles: $\mathrm{ND}_{2} \mathrm{OD}$ integrated areas after the co-deposition of $\mathrm{NO}$ molecules and $\mathrm{D}$ atoms. $\mathrm{ND}_{2} \mathrm{OD}$ yield is less than that of $\mathrm{NH}_{2} \mathrm{OH}$ at the same surface temperatures.

\subsubsection{Catalytic role of water}

In dark molecular clouds, the major component of molecular mantles covering dust grains is solid water. $\frac{[5]}{} \mathrm{A}$ water substrate should have an effect on the kinetic of surface reactions because it changes at least the environmental factors of the hydrogenation. Indeed, the $\mathrm{H}$ diffusion is dependent on the type of substrate ${ }^{\frac{46}{6}}$ and is known to affect the hydrogenation of $\mathrm{CO} . \sqrt[56]{6}$ The comparison of the efficiency of formation of hydroxylamine is presented in 
Figure 9. The blue curve, obtained in the $\{\mathrm{NO}+\mathrm{H}\}$ experiment on a porous ice substrate, has the same shape but a higher amplitude than the one obtained after the hydrogenation of NO on a gold substrate (in red). Therefore, we can conclude that the presence of water is helping the formation of hydroxylamine. The last line of Table 1 displays the amount of the different products. The consumption of $\mathrm{NO}$ is higher, the formation of $\mathrm{NH}_{2} \mathrm{OH}$ is also enhanced while the production of $\mathrm{N}_{2} \mathrm{O}$ is stable or slightly reduced. The higher consumption of $\mathrm{NO}$ is a precious indication. Actually we know that reaction 2 is barrierless and therefore that NO should be continuously consumed. The remaining amount of $\mathrm{NO}$ at the end of the experiment is probably due to the presence of the (reverse) abstraction reaction 8 . So we can conclude that the presence of water is limiting reaction 8 , probably by imposing geometrical constraints on the orientation of HNO.

Our DFT calculations (see Table 4 in the supporting information) indicate that the most stable geometry for $\mathrm{HNO}$ bound to water is via the $\mathrm{H}_{2} \mathrm{O}$...H-NO interaction. Then the $\mathrm{H}$ atom abstraction is more difficult due to geometrical constraints, and so limiting the abstraction reaction. If reaction 8 is less efficient, there are less chemical loops between HNO and NO and therefore the chemical desorption total efficiency is lesser. Moreover, water ice substrates typically impede the chemical desorption. ${ }^{[5254}$ We note that the total amount of NO-bearing products in presence of water (Table 1. $\left\{\mathrm{NO}+\mathrm{H}+\mathrm{H}_{2} \mathrm{O}\right\}$ experiment) is the highest of all experiments. There is no increase in $\mathrm{N}_{2} \mathrm{O}$ since its chemical pathway is not much changed. There is not more HNO formed, and the water does not help or even reduce the probability of having $\mathrm{NO}$ close to $\mathrm{HNO}$, because of its larger surface area.

\subsubsection{The possibility of back reaction $\mathrm{NH}_{2} \mathrm{OH}+\mathrm{H} \longrightarrow \mathrm{H}_{2} \mathrm{NO}+\mathrm{H}_{2}$}

To test this possibility, we first synthesize a $\mathrm{ND}_{2} \mathrm{OD}$ film in situ and later expose it to $\mathrm{H}$ atoms. The $\mathrm{ND}_{2} \mathrm{OD}$ is obtained by co-depositing $\{\mathrm{NO}+\mathrm{D}\}$ at $10 \mathrm{~K}$ and thus we heat the sample to $160 \mathrm{~K}$. At this temperature $\mathrm{ND}_{2} \mathrm{OD}$ does not desorb, but other species do (i.e $\mathrm{D}_{2}$, $\mathrm{NO}$, and $\mathrm{N}_{2} \mathrm{O}$ ). Then, the surface temperature is cooled to $10 \mathrm{~K}$ and $\mathrm{H}$ atoms (half the dose 


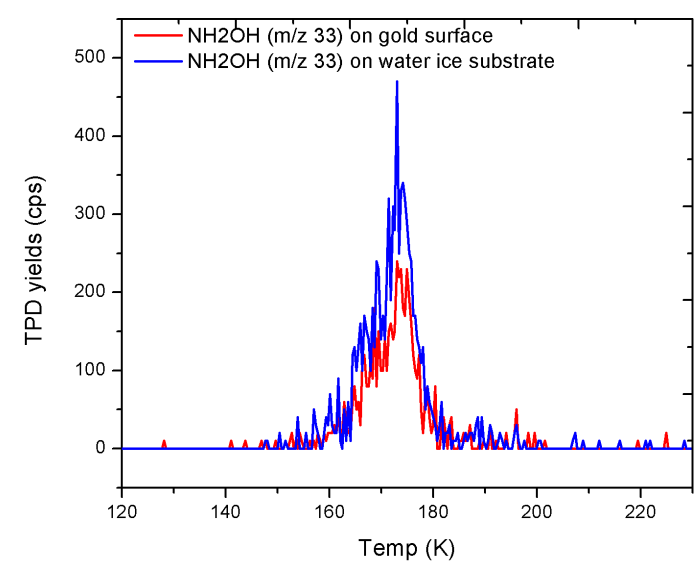

Figure 9: TPD profiles of $\mathrm{NH}_{2} \mathrm{OH}$ desorbing after $\{\mathrm{NO}+\mathrm{H}\}$ codeposition experiment on gold surface (red) and water ice substrate (blue), at the same sample temperature of $10 \mathrm{~K}$.

of the target molecule) are sent.

The top panel of Figure 10 shows that $\mathrm{ND}_{2} \mathrm{OD}$ is reduced by the addition of $\mathrm{H}$ atoms. The bottom panel shows a large peak of mass 35 . This mass can be attributed to NDHOD, or its isomer $\mathrm{ND}_{2} \mathrm{OH}$. This substitution reaction is unlikely to proceed directly, actually D bonds are usually slightly stronger than $\mathrm{H}$ bonds due to the shift of zero point energy. So the most probable case is that a loop of abstraction and addition occurs, making the substitution efficient. Our DFT calculations show that, in the gas phase, the $\mathrm{H}$ atom abstraction by $\mathrm{H}$ on the $\mathrm{NH}_{2}$ and $\mathrm{OH}$ group of $\mathrm{NH}_{2} \mathrm{OH}$ involve barriers around $1500 \mathrm{~K}$. They also show that the most stable geometry for $\mathrm{NH}_{2} \mathrm{OH}$ bound on our water cluster involves an $\mathrm{H}_{2} \mathrm{O}$.. $\mathrm{H}-\mathrm{ON}$ interaction (see Table 4 in the Supporting information). Therefore, the $\mathrm{H}$ atom abstraction from the $\mathrm{OH}$ group of $\mathrm{NH}_{2} \mathrm{OH}$ should be inhibited because of geometrical constraints and the back reaction toward the formation of $\mathrm{NHOH}$ favoured if tunneling can take place.

The abstraction- addition steps are the following:

$$
\mathrm{ND}_{2} \mathrm{OD}+\mathrm{H} \longrightarrow \mathrm{NDOD}+\mathrm{HD}
$$



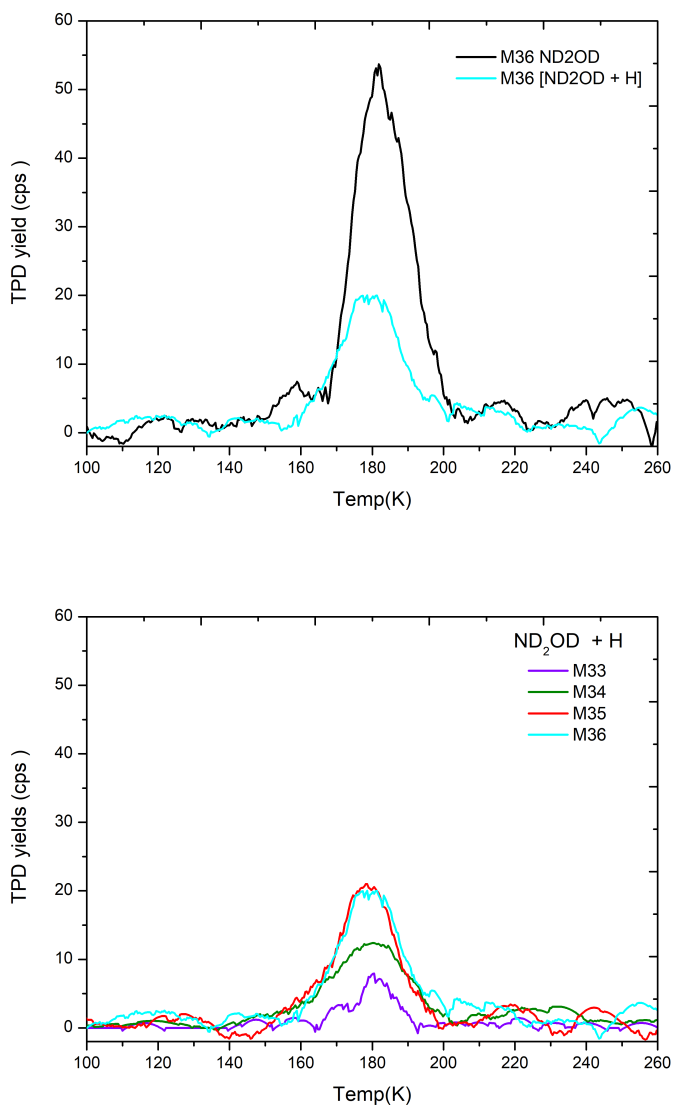

Figure 10: Top panel: TPD profiles of initial $\mathrm{ND}_{2} \mathrm{OD}$ (black curve) and remaining $\mathrm{ND}_{2} \mathrm{OD}$ (cyan curve) after reacting with $\mathrm{H}$ atoms at $10 \mathrm{~K}$. Bottom panel: TPD profiles of products detected after exposure of $\mathrm{H}$ atoms onto a $\mathrm{ND}_{2} \mathrm{OD}$ film. $\mathrm{m} / \mathrm{z} 35$ (red curve), $\mathrm{m} / \mathrm{z} 34$ (green curve), $m / z 33$ (violet curve), and $m / z 36$ (cyan curve) 


$$
\mathrm{NDOD}+\mathrm{H} \longrightarrow \mathrm{NDHOD}
$$

The presence of mass 34 could only be due to the cracking pattern of $\mathrm{ND}_{2} \mathrm{OD}$. But in this case, it should be around a tenth of the mass 36 . Therefore a large fraction of the mass 34 is probably the doubly hydrogenated hydroxylamine. This would be the indication that the abstraction - addition mechanism is probably occurring on the $\mathrm{ND}_{2}$ group more than on the OD group (leading to simple hydrogenation). Even if this is speculative because we know that proton exchange is occurring during the TPD ${ }^{57-59}$ it is in agreement with our theoretical calculations showing that the back hydrogen abstraction reaction should favour the $\mathrm{NHOH}$ formation.

\subsubsection{Binding energies}

The TPDs performed in this work allow us to determine the binding energies of NO, $\mathrm{NH}_{2} \mathrm{OH}$ and $\mathrm{N}_{2} \mathrm{O}$. These values, shown on Table 1 in the Supporting information, are compared to the values calculated in the present study and to those given by the semiempirical model developped by Wakelam et al. ${ }^{46}$ The agreement is good.

\section{DISCUSSION AND CONCLUSIONS}

\subsection{Summary of the results}

Our experimental re-investigation of the $\mathrm{NO}+\mathrm{H}$ reactive system has demonstrated the following points: (i) it exists an activation barrier to the $\mathrm{H}+\mathrm{HNO}$ reaction, (ii) this barrier is likely to be crossed at low temperature through quantum tunneling, (iii) the direct evidence of the back reaction $\mathrm{NH}_{2} \mathrm{OH}+\mathrm{H}$ has been shown, which reminds us of the importance of taking into account this process. Indirect evidence of the $\mathrm{H}+\mathrm{HNO}$ back reaction has also been provided. (iv) Water has a catalytic role. It increases the efficiency 
of $\mathrm{H}$ additions probably by reducing the efficiency of the back reaction $\mathrm{HNO}+\mathrm{H} \longrightarrow$ $\mathrm{NO}+\mathrm{H}_{2}$. Alternatively, it is the water propensity to retain the products after reactions have occurred or, in other words, its property of reducing the chemical desorption can also partly explain why more products are obtained on a water ice substrate.

Our theoretical calculations corroborate these experimental findings and quantum chemistry help us to understand our results. More precisely we calculated at the MO6-2X level within the cluster approach :

$$
\begin{aligned}
& \mathrm{H}+\mathrm{NO} \longrightarrow \mathrm{HNO}: \text { no barrier } \\
& \mathrm{H}+\mathrm{HNO} \longrightarrow \mathrm{NO}+\mathrm{H}_{2} \text { : geometrically unfavored on water } \\
& \mathrm{H}+\mathrm{HNO} \longrightarrow \mathrm{NH}_{2} \mathrm{O} \text { : barrier of } 734 \mathrm{~K} \\
& \mathrm{H}+\mathrm{NH}_{2} \mathrm{O} \longrightarrow \mathrm{NH}_{2} \mathrm{OH} \text { : no barrier }
\end{aligned}
$$

At the M06-2X level in the gaze phase:

$$
\begin{aligned}
& \mathrm{H}+\mathrm{HNO} \longrightarrow \mathrm{NHOH} \text { : barrier of } 8167 \mathrm{~K} \\
& \mathrm{H}+\mathrm{NHOH} \longrightarrow \mathrm{NH}_{2} \mathrm{OH} \text { : no barrier } \\
& \mathrm{H}+\mathrm{NH}_{2} \mathrm{OH} \longrightarrow \mathrm{NH}_{2} \mathrm{O}+\mathrm{H}_{2} \text { : barrier of } 1528 \mathrm{~K} \\
& \mathrm{H}+\mathrm{NH}_{2} \mathrm{OH} \longrightarrow \mathrm{NHOH}+\mathrm{H}_{2} \text { : barrier of } 1540 \mathrm{~K}
\end{aligned}
$$

\subsection{New insights into the catalytic role of dust and water ice}

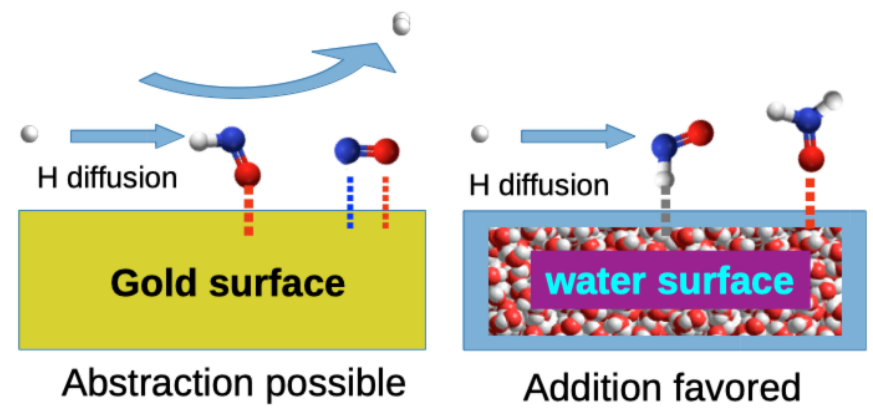

Figure 11: Schematic view of the role of water ice, compared with a gold surface, in the abstraction reaction $\mathrm{H}+\mathrm{HNO}$. Due to $\mathrm{H}$-bonding in a water environment, the $\mathrm{HNO}$ orientation does not favor $\mathrm{H}$ abstraction, despite its very low barrier in the gas phase 
Faced with the difficulty of finding effective reaction pathways leading to hydrogenation of molecules in the gas phase, interstellar dust grains have long been identified as a probable source of $\mathrm{H}$ additions. ${ }^{60}$ Cold surfaces are said to be catalytic centres thanks to four main properties. i) The grains collect species coming from the gas phase and promote encounters. ii) The grains act as third bodies and are able to dissipate excess energy. For this, the case of $\mathrm{H}_{2}$ is emblematic. The $\mathrm{H}+\mathrm{H} \longrightarrow \mathrm{H}_{2}+h v$ reaction (where $h v$ is a photon to remind that it is a radioactive recombination), is highly inefficient in the gas phase for such a small system. Here, the dust grains act as a third body and dissipate the excess energy of the reaction. iii) In addition to accretion, property i), the grains considerably increase the interaction time of the reactive partners. In the gas phase, once the collision is over, reactants move away from each other (if the reaction does not proceed). On the contrary, in the solid phase, reagents can easily form long-life complexes simply by being in two adjacent adsorption sites, and improve the overall efficiency of the reaction. Also in the case of reactions with an important barrier, solid-state chemistry allows hydrogenation to proceed by quantum tunnelling.

iv) Dust grains modify the reaction barriers, and especially can lower them, or as we can see in our study, the particular environment may impose a geometric constraint on the adsorbate and hinder certain reaction pathways that could have been fast in the gas phase. Figure 11 illustrates this aspect. Calculations have shown that HNO forms a $\mathrm{H}$ bond with an oxygen atom in the water cluster, limiting the access of $\mathrm{H}$ atoms that would diffuse at the entrance of the abstraction channel. Therefore, in this case, even if the hydrogenation reaction of HNO has a moderate barrier $(1200 \mathrm{~K})$ and is certainly higher than that of the abstraction reaction channel (in the gas phase), the addition reaction is favoured (right sketch in Fig. 11). On the gold substrate, there is less geometric stress on the entry channel of the abstraction reaction, and thanks to its low barrier, it becomes a competitive reactive pathway. Therefore, we would like to add an important piece of evidence resulting from this study: v) the molecular environment (such as $\mathrm{H}_{2} \mathrm{O}$ ice), can change the balance of the 
different competitive reactive pathways, and most importantly, the $\mathrm{H}$ bond can prevent an abstraction reaction. Thus, our studies seem to show that cosmic grains not only have a catalytic role in amplifying reactivity, but also a catalytic role in guiding reactions, which can reduce the diversity of reactive pathways on grains.

\subsection{Astrophysical implications and conclusions}

Our present study does not fundamentally change the conclusions of the previous experimental works. At low temperatures, hydroxylamine is the major product of the direct hydrogenation of NO. However, if the grains temperature increases, hydrogenation becomes less efficient. Back reactions (abstraction reactions) have to be taken into account. In this reactive scheme, and under the assumption that $\mathrm{H}$ atoms are the most abundant reaction partner on interstellar dust grains, their accretion can produce in situ radicals, even from stable molecules such as $\mathrm{NH}_{2} \mathrm{OH}$ that would already be accreted on the grain. In our case this radical is $\mathrm{NHOH}$. These radicals, issued from hydrogenation of saturated molecules, could be the carrier of a new generation of COMs. In Dulieu et al. 61 the formation of formamide $\left(\mathrm{NH}_{2} \mathrm{CHO}\right)$, is thought to be the result of the reaction of such radicals, and therefore, it is possible that the absence of detection of hydoxylamine in space is not due to low formation efficiency, but more likely to its further chemical evolution, in particular towards formamide if some $\mathrm{H}_{2} \mathrm{CO}$ is also adsorbed on grains. The presence of such in situ radicals produced by hydrogenation has already been used to form COMs. $\underline{62}$ In the present case, because we have measured a fast inclusion of $\mathrm{D}$ in $\mathrm{NH}_{2} \mathrm{OH}$ (Fig. 10), and found a low barrier to abstraction, we can identify the $\mathrm{NHOH}$ radical as a potential important missing link of the solid phase chemistry. In this way, $\mathrm{NH}_{2} \mathrm{OH}$ is not the end of the NO hydrogenation, but a step toward inclusion of $\mathrm{N}$ in the skeleton of COMs.

Our final conclusion is more general and concerns the method. Conducted independently, both quantum chemistry and laboratory studies lead to conclusions that may be open to discussion, while when they are combined, they can be very conclusive. We believe 
that it is now possible to disentangle complex chemical networks at play on cold surfaces through quantitative and various measurements, and to perform advanced quantum calculations that lift shadows and bring decisive arguments. Thanks to this synergy, the COMs synthesis pathways on interstellar grains are beginning to reveal their secrets.

\section{Acknowledgement}

TN thanks the Labex Michem program for her PHD grant. This work was supported by the Programme National "Physique et Chimie du Milieu Interstellaire" (PCMI) of CNRS/INSU with INC/INP co-funded by CEA and CNES, and by the DIM-ACAV+, a funding program of the Region Ile de France. This work was granted access to the HPC resources of [TGCC/CINES/IDRIS] under the allocation 2018 [A0040805116] made by GENCI.

\section{Supporting Information Available}

- The comparison of the binding energies of $\mathrm{NO}, \mathrm{NH}_{2} \mathrm{OH}$, and $\mathrm{N}_{2} \mathrm{O}$ between experimental data and models

- Energy barriers on the $\mathrm{H}+\mathrm{HNO}$ reactions paths: Energies relative to $\mathrm{H}+\mathrm{HNO}$ are in $\mathrm{kJ} / \mathrm{mol}$ and are corrected for the unscaled ZPE energies. Basis sets are: ${ }^{1}$ aug-cc-pVTZ, ${ }^{2} \mathrm{cc}-\mathrm{pVQZ}-\mathrm{F} 12,{ }^{3} 6-311++\mathrm{G}(\mathrm{d}, \mathrm{p}),{ }^{4} \mathrm{CBS},{ }^{5} \mathrm{cc}-\mathrm{pVQZ}$

- Energy barries on the $\mathrm{H}+\mathrm{H}_{2} \mathrm{NOH}$ reaction paths: M062X/aug-cc-pVTZ energies relative energies to $\mathrm{H}+\mathrm{H}_{2} \mathrm{NOH}$ are in $\mathrm{kJ} / \mathrm{mol}$ and are corrected for the unscaled ZPE energies

- Structure and binding energies of $\mathrm{NO}, \mathrm{HNO}, \mathrm{H}_{2} \mathrm{NO}$, and $\mathrm{NH}_{2} \mathrm{OH}$ on the 4 water clusters: Binding energies $(\Delta \mathrm{E})$ in $\mathrm{kJ} / \mathrm{mol}$ are calculated at the M06X/6-311++G(d,p) 
level as the difference between the molecule bond to the cluster and the sum of the energies of the molecule and the energy of the cluster. They are corrected for unscaled zero point energies calculated at the same level

- Structure for the $\mathrm{H}-\mathrm{HNO}-4 \mathrm{H}_{2} \mathrm{O}$ transition state and energy barrier with respect to $\mathrm{H}+$ $\mathrm{HNO}-4 \mathrm{H}_{2} \mathrm{O}$ : The energy barrier in $\mathrm{kJ} / \mathrm{mol}$ is calculated at the M062X/6-311++G(d,p) level. It is corrected for the unscaled zero point energies calculated at the same level

\section{References}

(1) Ando, R. et al. Diverse Nuclear Star-forming Activities in the Heart of NGC 253 Resolved with 10-pc-scale ALMA Images. Astrophys. J. 2017, 849, 81.

(2) Lopez-Sepulcre, A.; Jaber, A. A.; Mendoza, E.; Lefloch, B.; Ceccarelli, C.; Vastel, C.; Bachiller, R.; Cernicharo, J.; Codella, C.; Kahane, C.; Kama, M.; Tafalla, M. Shedding light on the formation of the pre-biotic molecule formamide with ASAI. Mon. Not. R. Astron. Soc. 2015, 449, 2438-2458.

(3) Pagani, L.; Favre, C.; Goldsmith, P. F.; Bergin, E. A.; Snell, R.; Melnick, G. The complexity of Orion: an ALMA view. I. Data and first results. Astron. Astrophys. 2017, 604, A32.

(4) Cernicharo, J.; Marcelino, N.; Roueff, E.; Gerin, M.; Jiménez-Escobar, A.; Caro, G. M. M. Discover of the methoxy radical, $\mathrm{CH}_{3} \mathrm{O}$, toward $\mathrm{B} 1$ : Dust grain and gas phase chemistry in cold dark clouds. Astrophys. J. 2012, 759, L43.

(5) Ceccarelli, C. et al. Seeds Of Life In Space (SOLIS): The Organic Composition Diversity at 300-1000 au Scale in Solar-type Star-forming Regions. Astrophys. J. 2017, 850, 176.

(6) Shannon, R. J.; Caravan, R. L.; Blitz, M. A.; Heard, D. E. A combined experimental and theoretical study of reactions between the hydroxyl radical and oxygenated 
hydrocarbons relevant to astrochemical environments. Phys. Chem. Chem. Phys.: PCCP 2014, 16, 3466-78.

(7) Dulieu, F.; Amiaud, L.; Congiu, E.; Fillion, J.-H.; Matar, E.; Momeni, A.; Pirronello, V.; Lemaire, J. L. Experimental evidence for water formation on interstellar dust grains by hydrogen and oxygen atoms. Astron. Astrophys. 2010, 512, A30.

(8) Jing, D.; He, J.; Brucato, J.; De Sio, A.; Tozzetti, L.; Vidali, G. On water formation in the interstellar medium: Laboratory study of the $\mathrm{O}+\mathrm{D}$ reaction on surfaces. Astrophys. J. 2011, 741, L9.

(9) Oba, Y.; Watanabe, N.; Kouchi, A.; Hama, T.; Pirronello, V. Experimental Study of $\mathrm{CO}_{2}$ Formation by Surface Reactions of Non-energetic OH Radicals with CO Molecules. Astrophys. J. Lett. 2010, 712, L174-L178.

(10) Ioppolo, S.; van Boheemen, Y.; Cuppen, H. M.; van Dishoeck, E. F.; Linnartz, H. Surface formation of CO2 ice at low temperatures. Mon. Not. R. Astron. Soc. 2011, 413, 2281-2287.

(11) Noble, J. A.; Dulieu, F.; Congiu, E.; Fraser, H. J. $\mathrm{CO}_{2}$ formation in quiescent clouds: An experimental study of the $\mathrm{CO}+\mathrm{OH}$ pathway. Astrophys. J. 2011, 735, 121.

(12) Minissale, M.; Congiu, E.; Manicò, G.; Pirronello, V.; Dulieu, F. $\mathrm{CO}_{2}$ formation on interstellar dust grains: a detailed study of the barrier of the $\mathrm{CO}+\mathrm{O}$ channel. Astron. Astrophys. 2013, 559, A49.

(13) Minissale, M.; Loison, J.-C.; Baouche, S.; Chaabouni, H.; Congiu, E.; Dulieu, F. Solidstate formation of $\mathrm{CO}_{2}$ via the $\mathrm{H}_{2} \mathrm{CO}+\mathrm{O}$ reaction. Astron. Astrophys. 2015, 577, A2.

(14) Hiraoka, K.; Sato, T.; Sato, S.; Sogoshi, N.; Yokoyama, T.; Takashima, H.; Kitagawa, S. Formation of Formaldehyde by the Tunneling Reaction of $\mathrm{H}$ with Solid CO at $10 \mathrm{~K}$ Revisited. Astrophys. J. 2002, 577, 265-270. 
(15) Watanabe, N.; Kouchi, A. Efficient Formation of Formaldehyde and Methanol by the Addition of Hydrogen Atoms to $\mathrm{CO}$ in $\mathrm{H}_{2} \mathrm{O}-\mathrm{CO}$ Ice at 10 K. Astrophys. J. 2002, 571, L173-L176.

(16) Fuchs, G. W.,; Cuppen, H. M.,; Ioppolo, S.,; Romanzin, C.,; Bisschop, S. E.,; Andersson, S.,; van Dishoeck, E. F.,; Linnartz, H., Hydrogenation reactions in interstellar CO ice analogues - A combined experimental/theoretical approach. Astron. Astrophys. 2009, $505,629-639$.

(17) Minissale, M.; Fedoseev, G.; Congiu, E.; Ioppolo, S.; Dulieu, F.; Linnartz, H. Solid state chemistry of nitrogen oxides-Part I: surface consumption of NO. Phys. Chem. Chem. Phys. 2014, 16, 8257-8269.

(18) Ioppolo, S.; Fedoseev, G.; Minissale, M.; Congiu, E.; Dulieu, F.; Linnartz, H. Solid state chemistry of nitrogen oxides-Part II: surface consumption of $\mathrm{NO}_{2}$. Phys. Chem. Chem. Phys. 2014, 16, 8270-8282.

(19) Minissale, M.; Moudens, A.; Chaabouni, H.; ; Baouche, S.; Dulieu, F. Hydrogenation of CO-bearing species on grains: unexpected chemical desorption of CO. Mon. Not. R. Astron. Soc. 2016, 458, 2953-2961.

(20) Velilla Prieto, L.; Sánchez Contreras, C.; Cernicharo, J.; Agúndez, M.; QuintanaLacaci, G.; Alcolea, J.; Bujarrabal, V.; Herpin, F.; Menten, K. M.; Wyrowski, F. New $\mathrm{N}$-bearing species towards $\mathrm{OH} 231.8+4.2$. $\mathrm{HNCO}, \mathrm{HNCS}, \mathrm{HC}_{3} \mathrm{~N}$, and NO. Astron. Astrophys. 2015, 575, A84.

(21) Akyilmaz, M.; Flower, D. R.,; Hily-Blant, P.,; Pineau des Forêts, G.,; Walmsley, C. M., The depletion of NO in pre-protostellar cores *. Astron. Astrophys. 2007, 462, 221-230.

(22) Liszt, H. S.; Turner, B. E. Microwave detection of interstellar NO. Astrophys. J. Lett. 1978, 224, L73-L76. 
(23) Congiu, E.; Chaabouni, H.; Laffon, C.; Parent, P.; Baouche, S.; Dulieu, F. Efficient surface formation route of interstellar hydroxylamine through NO hydrogenation. I. The submonolayer regime on interstellar relevant substrates. J. Chem. Phys. 2012, 137, 054713.

(24) He, J.; Vidali, G.; Lemaire, J.-L.; Garrod, R. T. Formation of Hydroxylamine on dust grains via ammonia oxidation. Astrophys. J. 2015, 799, 49.

(25) Fedoseev, G.; Chuang, K.-J.; van Dishoeck, E. F.; Ioppolo, S.; Linnartz, H. Simultaneous hydrogenation and UV-photolysis experiments of NO in CO-rich interstellar ice analogues; linking $\mathrm{HNCO}, \mathrm{OCN}^{-}, \mathrm{NH}_{2} \mathrm{CHO}$, and $\mathrm{NH}_{2} \mathrm{OH}$. Mon. Not. R. Astron. Soc. 2016, 460, 4297-4309.

(26) Congiu, E.; Fedoseev, G.; Ioppolo, S.; Dulieu, F.; Chaabouni, H.; Baouche, S.; Lemaire, J. L.; Laffon, C.; Parent, P.; Lamberts, T.; Cuppen, H. M.; Linnartz, H. NO ice hydrogenation: A soild pathway to $\mathrm{NH}_{2} \mathrm{OH}$ formation in space. Astrophysical. J. 2012, 750, L12.

(27) Fedoseev, G.; Ioppolo, S.; Lamberts, T.; Zhen, J. F.; Cuppen, H. M.; Linnartz, H. Efficient surface formation route of interstellar hydroxylamine through NO hydrogenation. II. The multilayer regime in interstellar relevant ices. J. Chem. Phys. 2012, $137,054714$.

(28) Oba, Y.; Chigai, T.; Osamura, Y.; Watanabe, N.; Kouchi, A. Hydrogen isotopic substitution of solid methylamine through atomic surface reactions at low temperatures: A potential contribution to the $\mathrm{D} / \mathrm{H}$ ratio of methylamine in molecular clouds. Meteorit. Planet. Sci. 2014, 49, 117-132.

(29) Kobayashi, H.; Hidaka, H.; Lamberts, T.; Hama, T.; Kawakita, H.; Kästner, J.; Watanabe, N. Hydrogenation and Deuteration of $\mathrm{C}_{2} \mathrm{H}_{2}$ and $\mathrm{C}_{2} \mathrm{H}_{4}$ on Cold Grains: A Clue to 
the Formation Mechanism of $\mathrm{C}_{2} \mathrm{H}_{6}$ with Astronomical Interest. Astrophys. J. 2017, 837, 155.

(30) Oba, Y.; Tomaru, T.; Lamberts, T.; Kouchi, A.; Watanabe, N. An infrared measurement of chemical desorption from interstellar ice analogues. Nat. Astron. 2018, 2, 228-232.

(31) Glarborg, P.; stberg, M.; Alzueta, M. U.; Dam-Johansen, K.; Miller, J. A. The recombination of hydrogen atoms with nitric oxide at high temperatures. Symposium (International) on Combustion 1998, 27, 219 - 226, Twenty-Seventh Sysposium (International) on Combustion Volume One.

(32) Soto, M. R.; Page, M. Ab initio variational transition-state-theory reactionrate calculations for the gas - phase reaction $\mathrm{H}+\mathrm{HNO} \rightarrow \mathrm{H}_{2}+\mathrm{NO}$. J. Chem. Phys. 1992, 97, $7287-7296$.

(33) Nguyen, H. M. T.; Zhang, S.; Peeters, J.; Truong, T. N.; Nguyen, M. T. Direct ab initio dynamics studies of the reactions of $\mathrm{HNO}$ with $\mathrm{H}$ and $\mathrm{OH}$ radicals. Chem. Phys. Lett. 2004, 388, $94-99$.

(34) Vasyunin, A. I.; Herbst, E. Reactive desorption and radiative association as possible drivers of complex molecule formation in the cold interstellar medium. Astrophys. J. 2013, 769, 34 .

(35) Ruaud, M.; Wakelam, V.; Hersant, F. Gas and grain chemical composition in cold cores as predicted by the Nautilus three-phase model. Mon. Not. R. Astron. Soc. 2016, $459,3756-3767$.

(36) Cuppen, H. M.; Walsh, C.; Lamberts, T.; Semenov, D.; Garrod, R. T.; Penteado, E. M.; Ioppolo, S. Grain Surface Models and Data for Astrochemistry. Space Sci. Rev. 2017, $212,1-58$. 
(37) Vasyunin, A. I.; Caselli, P.; Dulieu, F.; Jiménez-Serra, I. Formation of Complex Molecules in Prestellar Cores: A Multilayer Approach. Astrophys. J. 2017, 842, 33.

(38) Minissale, M.; Nguyen, T.; Dulieu, F. Experimental study of the penetration of oxygen and deuterium atoms into porous water ice. Astron. Astrophys. 2019, 622, A148.

(39) Zhao, Y.; Truhlar, D. G. The M06 suite of density functionals for main group thermochemistry, thermochemical kinetics, noncovalent interactions, excited states, and transition elements: two new functionals and systematic testing of four M06-class functionals and 12 other functionals. Theor. Chem. Acc. 2008, 120, 215-241.

(40) Korth, M.; Grimme, S. Mindless DFT Benchmarking. J. Chem. Theory Comput. 2009, 5, 993-1003, PMID: 26609608.

(41) Raghavachari, K.; Trucks, G. W.; Pople, J. A.; Head-Gordon, M. A fifth-order perturbation comparison of electron correlation theories. Chem. Phys. Lett. 1989, 157, 479 483.

(42) Knizia, G.; Adler, T. B.; Werner, H.-J. Simplified CCSD(T)-F12 methods: Theory and benchmarks. J. Chem. Phys. 2009, 130, 054104.

(43) Peterson, K. A.; Adler, T. B.; Werner, H.-J. Systematically convergent basis sets for explicitly correlated wavefunctions: The atoms $\mathrm{H}, \mathrm{He}, \mathrm{B}-\mathrm{Ne}$, and $\mathrm{Al}-\mathrm{Ar}$. J. Chem. Phys. 2008, 128, 084102.

(44) Sylvetsky, N.; Peterson, K. A.; Karton, A.; Martin, J. M. L. Toward a W4-F12 approach: Can explicitly correlated and orbital-based ab initio $\operatorname{CCSD}(\mathrm{T})$ limits be reconciled? J. Chem. Phys. 2016, 144, 214101.

(45) Karton, A.; Rabinovich, E.; Martin, J. M. L.; Ruscic, B. W4 theory for computational thermochemistry: In pursuit of confident sub-kJ/mol predictions. J. Chem. Phys. 2006, $125,144108$. 
(46) Wakelam, V.; Bron, E.; Cazaux, S.; Dulieu, F.; Gry, C.; Guillard, P.; Habart, E.; Hornekær, L.; Morisset, S.; Nyman, G.; Pirronello, V.; Price, S. D.; Valdivia, V.; Vidali, G.; Watanabe, N. $\mathrm{H}_{2}$ formation on interstellar dust grains: The viewpoints of theory, experiments, models and observations. Mol. Astrophys. 2017, 9, 1-36.

(47) M.J. Frisch,; G.W. Trucks,; H.B. Schlegel,; G.E. Scuseria,; M.A. Robb,; J.R. Cheeseman,; G. Scalmani,; V. Barone,; B. Mennucci,; G.A. Petersson, Gaussian09, Revision A. Inc., Wallingford CT. 2009, 121, 150-166.

(48) Werner, H.-J.; Knowles, P. J.; Knizia, G.; Manby, F. R.; Schtz, M. Molpro: a generalpurpose quantum chemistry program package. Wiley Interdisciplinary Reviews: Computational Molecular Science. 2012, 2, 242-253.

(49) Washida, N.; Akimoto, H.; Okuda, M. Nitrosyl hydride formed in the $\mathrm{H}+\mathrm{NO}+\mathrm{M}$ reaction system. J. Phys. Chem. 1978, 82, 2293-2299.

(50) Karton, A.; Sylvetsky, N.; Martin, J. M. L. W4-17: A diverse and high-confidence dataset of atomization energies for benchmarking high-level electronic structure methods. J. Comput. Chem. 2017, 38, 2063-2075.

(51) Fateley, W. G.; Bent, H. A.; Crawford, B. Infrared Spectra of the Frozen Oxides of Nitrogen. J. Chem. Phys. 1959, 31, 204-217.

(52) Dulieu, F.; Congiu, E.; Noble, J.; Baouche, S.; Chaabouni, H.; Moudens, A.; Minissale, M.; Cazaux, S. How micron-sized dust particles determine the chemistry of our Universe. Sci. Rep. 2013, 3, 1338.

(53) Minissale, M.; Fedoseev, G.; Congiu, E.; Ioppolo, S.; Dulieu, F.; Linnartz, H. Solid state chemistry of nitrogen oxides -Part I: surface consumption of NO. Phys. Chem. Chem. Phys. 2014, 16, 8257-8269. 
(54) Minissale, M.; Dulieu, F.,; Cazaux, S.,; Hocuk, S., Dust as interstellar catalyst. I. Quantifying the chemical desorption process. Astron. Astrophys. 2016, 585, A24.

(55) Boogert, A. A.; Gerakines, P. A.; Whittet, D. C. Observations of the Icy Universe. Annu. Rev. Astron. Astrophys. 2015, 53, 541-581.

(56) Watanabe, N.; Nagaoka, A.; Shiraki, T.; Kouchi, A. Hydrogenation of CO on Pure Solid CO and $\mathrm{CO}-\mathrm{H}_{2} \mathrm{O}$ Mixed Ice. Astrophys. J. 2004, 616, 638-642.

(57) R. Scott Smith,; C. Huang;; Kay*, B. D. Evidence for Molecular Translational Diffusion during the Crystallization of Amorphous Solid Water. J. Phys. Chem. B 1997, 101, 6123-6126.

(58) Mokrane, H.; Chaabouni, H.; Accolla, M.; Congiu, E.; Dulieu, F.; Chehrouri, M.; Lemaire, J. L. Experimental evidence for water formation via ozone hydrogenation on dust grains at $10 \mathrm{~K}$. Astrophys. J. 2009, 705, L195-L198.

(59) Dulieu, F.; Minissale, M.; Bockelée-Morvan, D. Production of $\mathrm{O}_{2}$ through dismutation of $\mathrm{H}_{2} \mathrm{O}_{2}$ during water ice desorption: a key to understanding comet $\mathrm{O}_{2}$ abundances. Astron. Astrophys. 2017, 597, A56.

(60) Gould, R. J.; Salpeter, E. E. The Interstellar Abundance of the Hydrogen Molecule. I. Basic Processes. Astrophys. J. 1963, 138, 393.

(61) Dulieu, F.; Nguyen, T.; Congiu, E.; Baouche, S.; Taquet, V. Efficient formation route of the prebiotic molecule formamide on interstellar dust grains. Mon. Not. R. Astron. Soc. Lett. 2019, 484, L119-L123.

(62) Chuang, K.-J.; Fedoseev, G.; Ioppolo, S.; van Dishoeck, E. F.; Linnartz, H. H-atom addition and abstraction reactions in mixed $\mathrm{CO}, \mathrm{H}_{2} \mathrm{CO}$ and $\mathrm{CH}_{3} \mathrm{OH}$ ices - an extended view on complex organic molecule formation. Mon. Not. R. Astron. Soc. 2015, 455, 1702-1712. 
Graphical TOC Entry

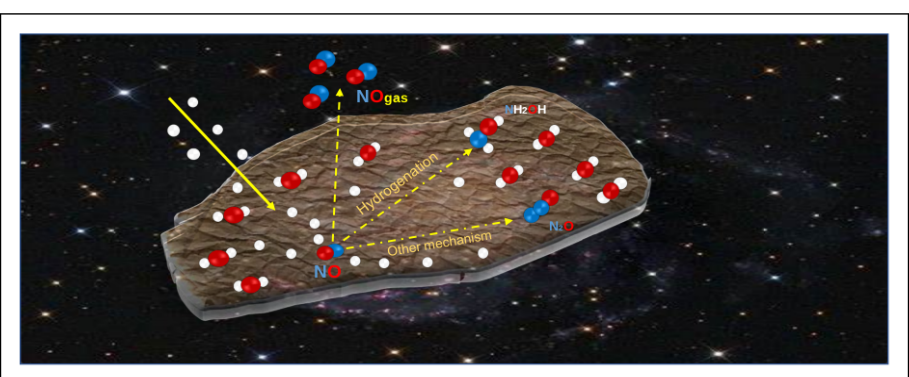

